\title{
Now I Know How Joan of Arc Felt: el mito de Juana de Arco y su legado en la moda y cultura visual contemporáneas
}

Now I Know How Joan of Arc Felt: o mito de Joana d'Arc e seu legado para a moda contemporânea e a cultura visual

Now I Know How Joan of Arc Felt: the myth of Joan of Arc and her legacy in contemporary fashion and visual culture

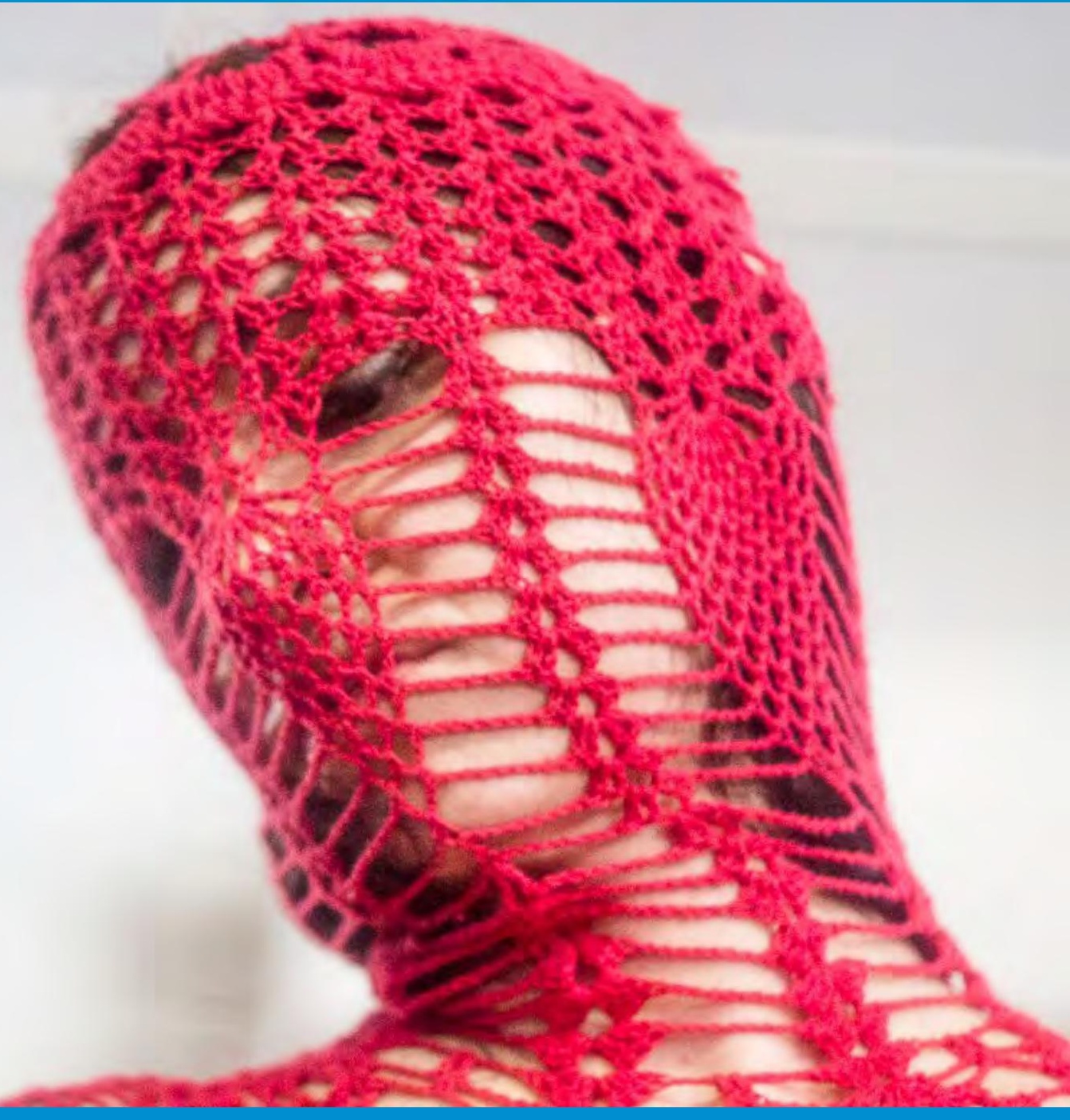




\section{Diana Lucía Gómez-Chacón ${ }^{1}$}

ORCID: https://orcid.org/0000-0002-7889-3158

[resumen] Christine de Pizan, una de las principales representantes de la Querella de las Mujeres - debate literario que a finales de la Edad Media reivindicó la virtud natural de la mujer - compuso en 1429, y, por lo tanto, en vida de la homenajeada, su Ditié de Jehanne d'Arc, dando origen a uno de los mitos femeninos más longevos de la historia. El presente trabajo analiza cómo Juana de Arco, convertida en icono de fortaleza, libertad, virilización y misticismo femeninos, ha sido, desde entonces, una constante en el mundo de la indumentaria y la moda, cobrando especial protagonismo en la pasarela contemporánea, de la mano de algunos de los principales diseñadores internacionales como Paco Rabanne, Jean Paul Gaultier, Alexander McQueen, John Galliano o Donatella Versace, quienes han hecho de la Doncella de Orleans una perfecta combinación de historia, leyenda y estética que no hace sino demostrar el valor semiótico y simbólico de la moda como expresión artística e instrumento de comunicación no verbal.

[palabras clave] Juana de Arco. Cross-dressing. Power-dressing. Virilización de la mujer. Moda contemporánea.

[resumo] Christine de Pizan, uma das principais representantes da Querelle de Femmes - um debate literário que no fim da Idade Média reivindicou a virtude natural das mulheres - composta em 1429, e, portanto, na vida do homenageado, a sua Ditié de Jehanne d'Arc, originou um dos mitos femininos mais antigos da história. 0 presente trabalho examina como Joana d'Arc, que se tornou ícone da força, da liberdade, da virilidade e do espiritualidade da mulher, tem sido desde então uma constante no mundo do vestuário e da moda, com protagonismo especial na passarela contemporânea conferido por alguns dos principais designers internacionais, como Paco Rabanne, Jean Paul Gaultier, Alexander McQueen, John Galliano e Donatella Versace, que fizeram da Donzela de Orléãns uma combinação perfeita de história, lenda e estética, demonstrando o valor semiótico e simbólico da moda como expressão artística e instrumento de comunicação não verbal.

\footnotetext{
1 Doctora en Historia del Arte por la Universidad Complutense de Madrid. Personal Docente e Investigador (PDI) en el CSDMM-Universidad Politécnica de Madrid. E-mail: diana.lucia@upm.es. https:// upm-es . academia.edu/DianaLuc\%C3\%ADaG\%C3\%B3mezChac\%C3\%B3n .
} 
[palavras-chave] Joana d'Arc. Cross-dressing. Power-dressing. Virilização das mulheres. Moda contemporânea.

[abstract] Christine de Pizan, one of the main representatives of the Querelle des femmes - a late medieval literary debate that claimed women's natural virtue - composed the Ditié de Jehanne d'Arc in 1429, that is to say, when her honoree was still alive. Thus, she gave rise to one of the longest-lived female myths in history. The present paper analyses how Joan of Arc, who has become an icon of female strength, freedom, virilization and mysticism, was since been a constant in the world of clothing and fashion, taking on special prominence in the contemporary catwalk, by some of the leading international designers such as Paco Rabanne, Jean Paul Gaultier, Alexander McQueen, John Galliano or Donatella Versace. All of them have transformed the Pucelle d'Orleans into a perfect combination of history, legend and aesthetics that proves fashion's semiotic and symbolic value, as an artistic expression and an instrument of nonverbal communication.

[keywords] Joan of Arc. Cross-dressing. Power-dressing. Women's virilization. Contemporary fashion.

Recebido em: 24-04-2020

Aprovado em: 25-06-2020 
It's almost like putting armor on a woman.

It's a very psychological way of dressing.

Alexander McQueen (1969-2010)

\section{Introducción}

A lo largo de los siglos la figura de Juana de Arco (†1431) se ha convertido en un auténtico mito e icono femenino que ha logrado traspasar los límites de la Historia y hacerse un importante hueco en el mundo de la moda y el estilismo. Ámbitos en los que se ha alzado como uno de los continuos referentes y fuentes de inspiración de algunos de los principales diseñadores contemporáneos que han hecho de la Doncella de Orleans un modelo de mujer fuerte, de continua actualidad y en constante transformación y evolución que forma parte intrínseca de la cultura visual del siglo XXI.

En 2010 Jean Paul Gaultier diseñó, en colaboración con la Monnaie de París, una colección de monedas de 10 euros dedicada a La France. Una Juana de Arco a caballo, con un look renovado, fue, precisamente, una de las figuras elegidas para decorar una de las mencionadas monedas. La misma Juana de Arco que encarnó Lisa Simpson en el capítulo 14 de la temporada 13 de Los Simpsons, estrenado el 17 de marzo de 2002 (figura 1). Encontramos otra versión animada de La Pucelle de mano del mangaka japonés Kōta Hirano, autor de Hellsing y Drifters. En este último manga, Juana de Arco es una offscouring al servicio del Rey Negro, una villana enloquecida tras su ejecución en la hoguera, que ahora luce cruces invertidas y que sueña con ver el mundo arder.

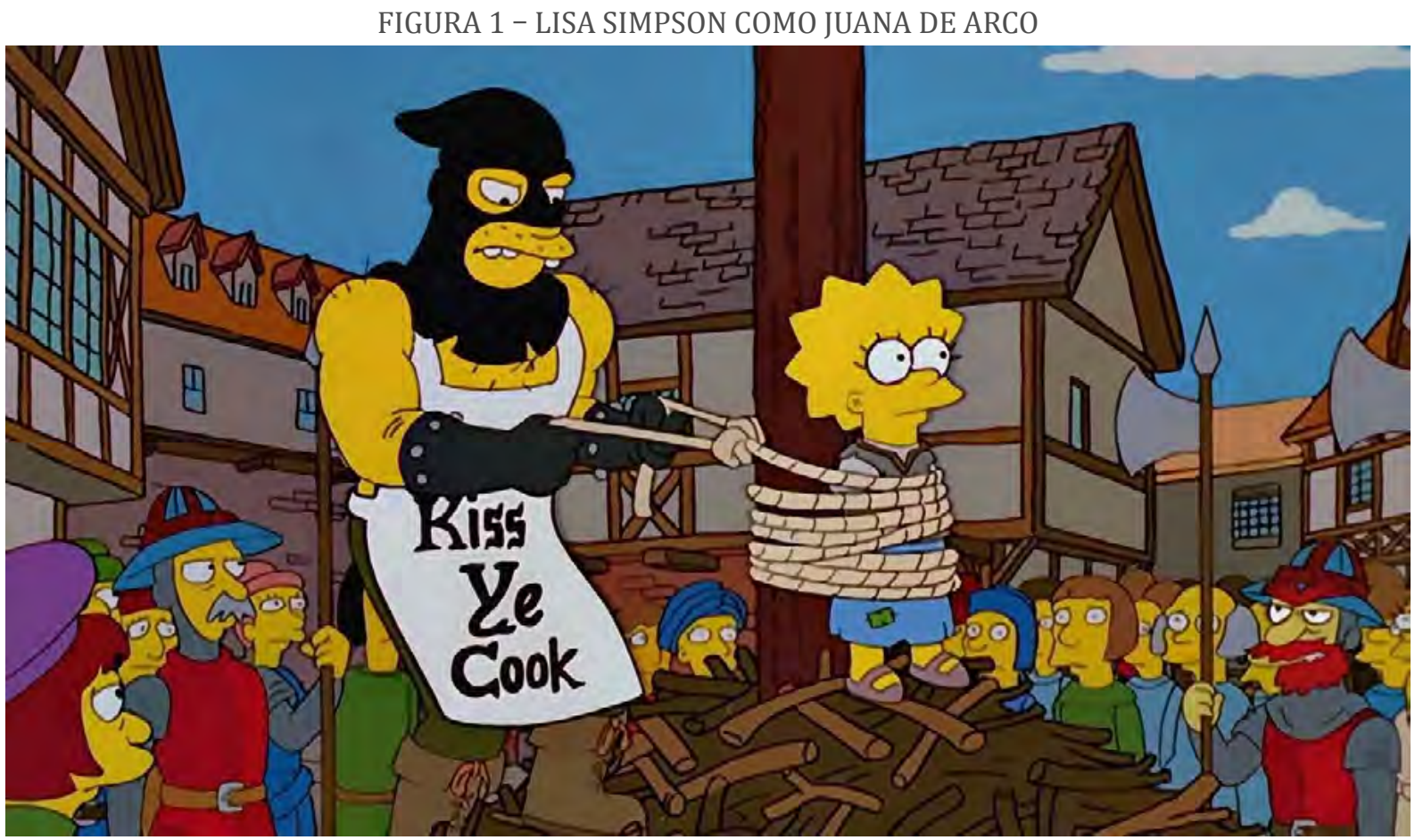

FUENTE: The Simpsons. Temporada 13, capítulo 14. Estrenado el 17 de marzo de 2002. 
Juana de Arco ha sido también rememorada por el cine y la música. Destaca la película muda francesa La Pasión de Juana de Arco (1928) del director y guionista danés Carl Theodor Dreyer, considerada uno de los grandes hitos del séptimo arte (BLAETZ, 2001, p. 56, 58 y 85-89). Años más tarde, en 1971, Leonard Cohen publicó su álbum Songs of Love and Hate, el cual cierra con la canción Joan of Arc, en la que la doncella mantiene un íntimo diálogo con el fuego que consume su cuerpo:

\author{
Ella dijo: "Estoy cansa de la guerra", \\ Quiero el tipo de trabajo que tenía antes, \\ Un vestido de novia o algo blanco \\ Para llevar sobre mi hinchado apetito ${ }^{2}$. \\ (COHEN, 1971)
}

El mismo icono francés fue recuperado por The Smiths en su tema Bigmouth Strikes Again (The Queen is Dead, 1986), en la mítica estrofa en la que ni las llamas consiguen que Juana renuncie a su walkman:

\author{
Y ahora sé cómo se sintió Juana de Arco, \\ Ahora sé cómo se sintió Juana de Arco, \\ Mientras las llamas subían hasta su nariz romana, \\ Y su walkman comenzaba a derretirse ${ }^{3}$.
}

(THE SMITHS, 1986)

El mito de Juana de Arco ha sido también resucitado por cantantes como Madonna y Katy Perry. La primera de ellas incluyó el tema Joan of Arc en su trigésimo álbum de estudio Rebel Heart (2015) y fue convertida en la Doncella de Orleans por el ya citado Jean Paul Gaultier - diseñador al que le unen años de colaboración, marcados por el emblemático corsé cónico del Blond Ambition Tour (1990) -, con motivo de su actuación en la MET Gala de 2018. Un look que volvería a lucir, en esta ocasión sustituyendo el blanco por el negro, en su polémica actuación en el festival de Eurovisión de 2019, celebrado en Tel Aviv (figura 2). Sin embargo, no era la primera vez que Jean Paul Gaultier rememoraba a través de sus diseños a Juana de Arco, musa de gran parte de los looks que componen su colección de alta costura otoño/invierno 2009-2010 (figura 3)

\footnotetext{
2 Tradução nossa para: "She said, I'm tired of the war / I want the kind of job I had before / A wedding dress or something white / To wear upon my swollen apetite".

3 Tradução nossa para: "And now I know how Joan of Arc felt / Now I know how Joan of Arc fet / As the flames rose to her Roman nose / And her Walkman started to melt".
} 


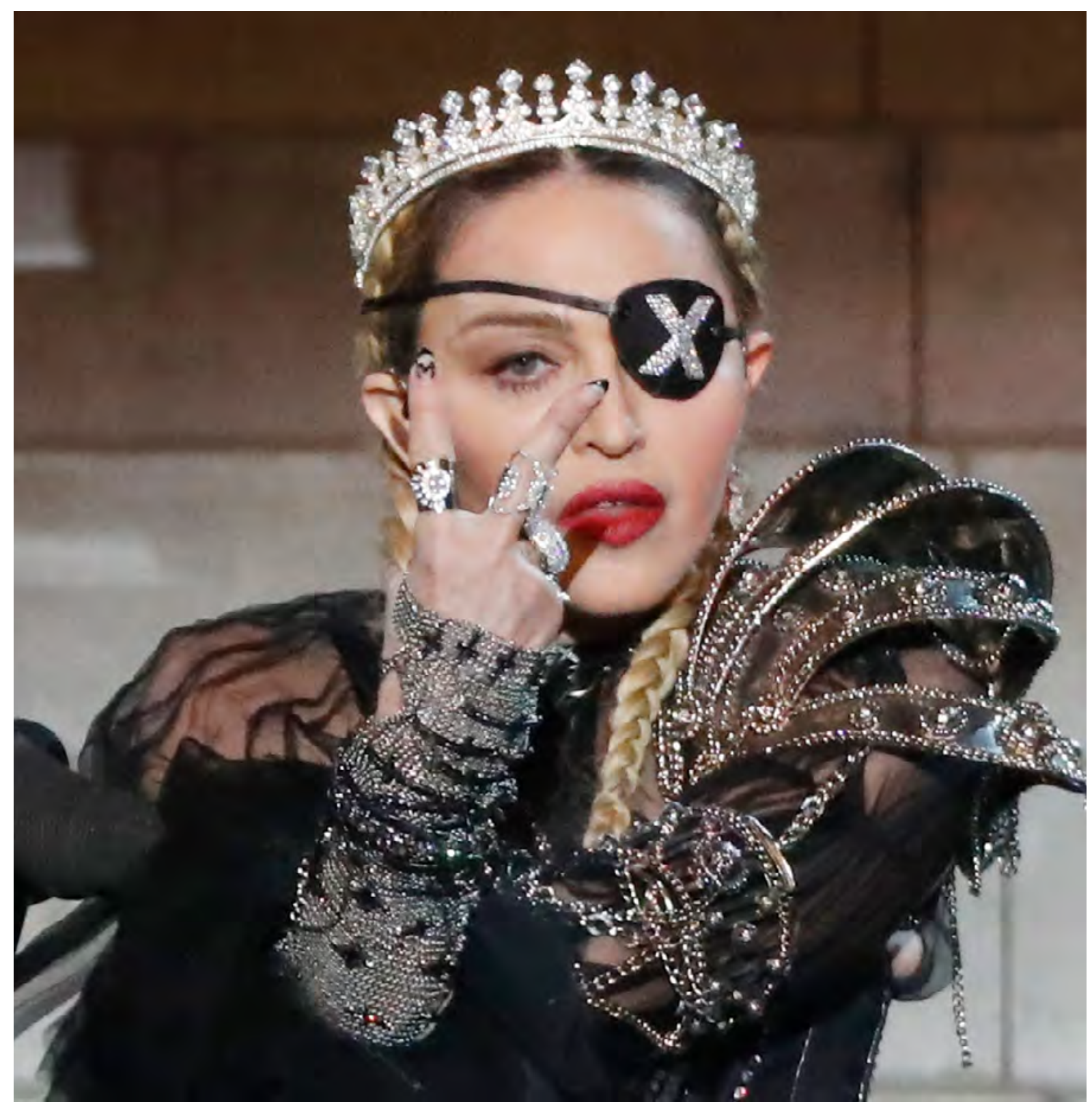

FUENTE: Revista Vanity Fair (13 de septiembre de 2019). 
FIGURA 3 - COLECCIÓN DE ALTA COSTURA OTOÑO/INVIERNO 2009/2010 DE JEAN PAUL GAULTIER

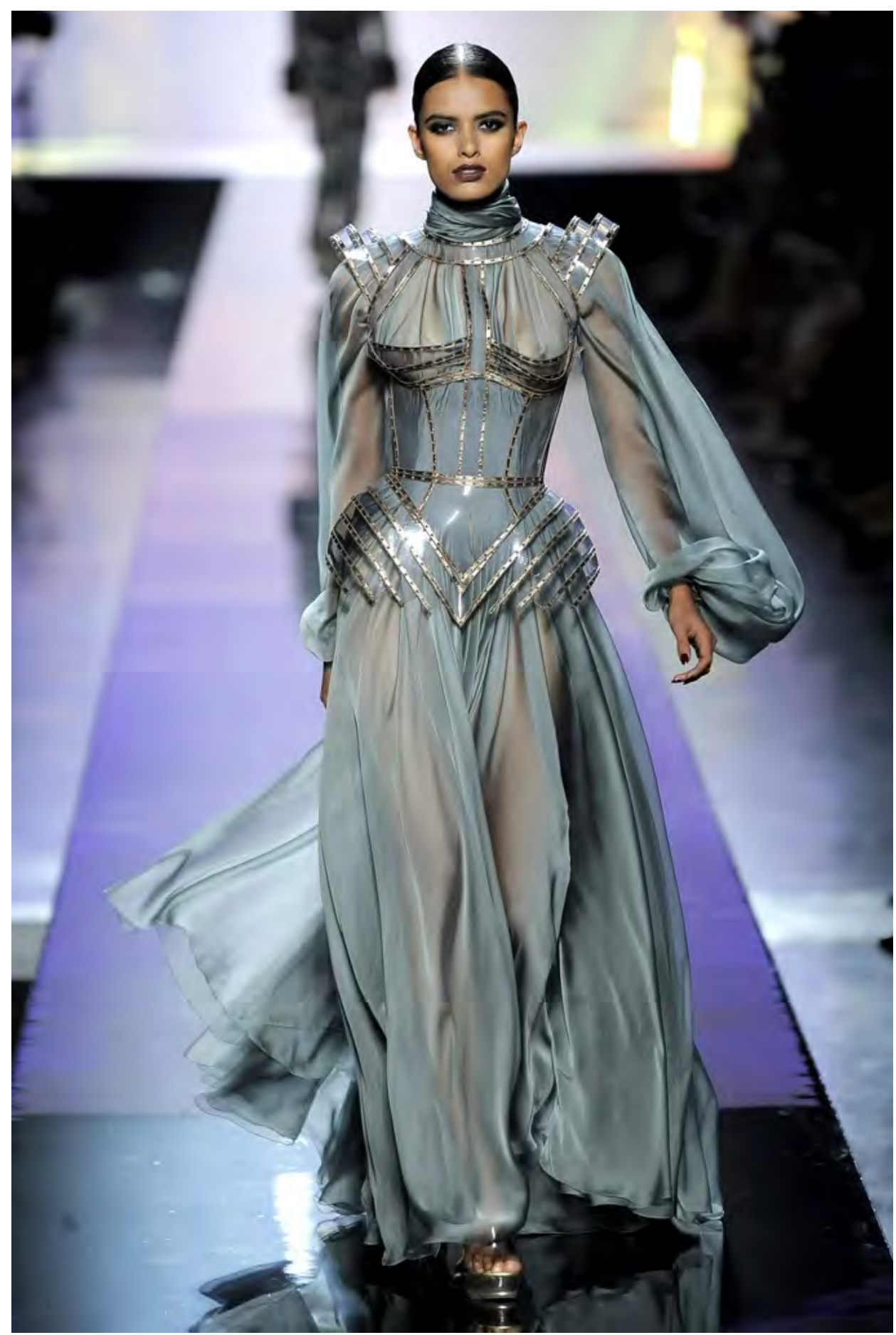

FUENTE: Revista Vogue. Disponible en: https://www.vogue.com/fashion-shows/fall-2009-couture/jeanpaul-gaultier/slideshow/collection. Acceso en: 4 abr. 2020. 
Por su parte, en el videoclip del tema Hey Hey Hey, del álbum Witness (2017), Katy Perry encarna a una María Antonieta que sueña con convertirse en una mujer fuerte, guerrera e independiente, como Juana de Arco:

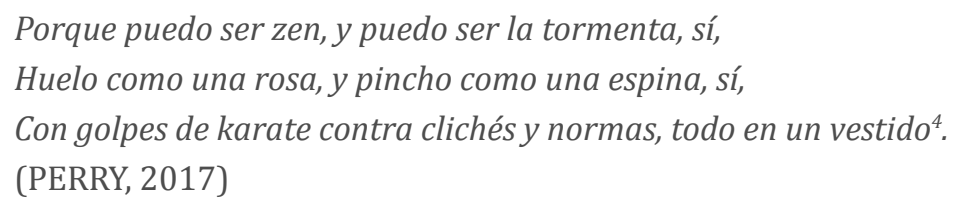

Un icono femenino el de Juana de Arco que, como se verá, a pesar de remontarse al siglo XV, sigue estando aún hoy muy presente en el imaginario de grandes diseñadores que hacen desfilar por la pasarela múltiples y variadas versiones del inmortal mito de $\mathrm{La} \mathrm{Pu-}$ celle. A continuación, se analizará la creación del mito de Juana de Arco, surgido en el siglo $\mathrm{XV}$, como depositaria del legado de las amazonas y las mujeres fuertes de la Biblia, el uso del cross-dressing a lo largo de la historia como muestra de fortaleza femenina, y el proceso de virilización de la mujer a través de la moda como expresión de power-dressing. Puntos todos ellos que ponen de manifiesto el valor semiótico y profundamente simbólico que, en ocasiones, adopta la moda, como poderoso instrumento visual y de comunicación no verbal.

\title{
La creación y recuperación de un mito: entre mujeres bíblicas y amazonas
}

En 1429 Christine de Pizan escribió Le Ditié de Jehanne d'Arc, un poema compuesto por sesenta y una estrofas, octavas o huitains, de ocho versos cada una, en el que la autora retomó la estructura propia de los romances y cantares de gesta, género literario medieval dedicado a la exaltación de las hazañas de guerreros. Christine de Pizan escribió esta obra en vida de la homenajeada, lo que constituye un auténtico hito en el ámbito literario de la época (CRANE, 1996, p. 312-313; ARDEN, 2003, p. 196; MORALES Y SEGURA, 2014, p. 7-8). En él exalta las primeras victorias de una mujer que logró "lo que cien mil hombres no fueron capaces de hacer". La obra de Pizan se enmarca, a su vez, en el movimiento conocido como la Querella de las Mujeres, del que la autora fue una de sus máximas representantes. Esta reclamaba para las mujeres la posibilidad de convertirse, al igual que los hombres, en un ser humano completo a través de la educación, y confería al sexo femenino una dignidad natural (VARGAS, 2016, p. 44 y 51-52).

En su Ditié, Christine de Pizan compara a Juana de Arco con algunas mujeres fuertes bíblicas, como Esther, Judith o Débora, quienes

\author{
Fueron damas de gran temple \\ A través de ellas, Dios liberó a su pueblo \\ De quienes lo tenían preso. \\ $Y$ de otras mujeres, yo sé \\ Que fueron también consideradas
}

\footnotetext{
${ }^{4}$ Tradução nossa para: "Cause I can be zen, a I can be the storm, yeah / Smell like a rose, and I pierce like a thorn, yeah / Karate chopping the clichés and norms all in a dress".
} 


\section{Como instrumento para sus milagros \\ ¡Pero más ha hecho a través de la Doncella! \\ (PIZAN, 1429, XXVIII)}

Encontramos una comparativa similar en el folio 101v de Ms Français 12476, fechado en 1440, que contiene la obra Le Champion des Dames de Martin Le Franc, conservada en la Biblioteca Nacional de Francia, en el que vemos a Juana de Arco, con larga cabellera y atuendo militar, representada junto a la figura de Judith, que introduce la cabeza de Holofernes en un saco que una joven sostiene abierto, a su derecha (figura 4). Juana de Arco se convierte entonces en un modelo de virtud femenina, teoría apoyada en escenas de la vida de la joven como la que decora el folio 60v de Les Vigiles de Charles VII de Martial d'Auvergne de hacia 1475-1500 (BnF, ms. Français 5054) en la que vemos a una Juana de Arco armada que persigue a caballo a un grupo de prostitutas. En su De claris mulieribus (1361-1362), Giovanni Bocaccio destacó ya algunas figuras de mujeres legendarias que adoptaron un rol propiamente masculino, como, por ejemplo, Camilla, reina de los Volscos, a la que alude también Álvaro de Luna en su Libro de las virtuosas e claras mugeres (1446):

E non sin grand trabajo crio la niña con leche de bestias. Como viniese en más rezia edad usava de los despojos de las bestias fieras, lançava dardos con los braços, e fondas, e arcos tendía, e traýa carcaje e seguía a los vencidos corriendos e vencialos. Todos los trabajos de las fembras desechó e guardó la flor de la virginidad sin corrompimiento más que las otras, e burlava del amor de los mancebos, e despreciava los casamientos de los nobles que la pidían, e diose toda al servicio de Diana a quien el padre la avía ofrescido. (LUNA, 1446, cap. XLV)

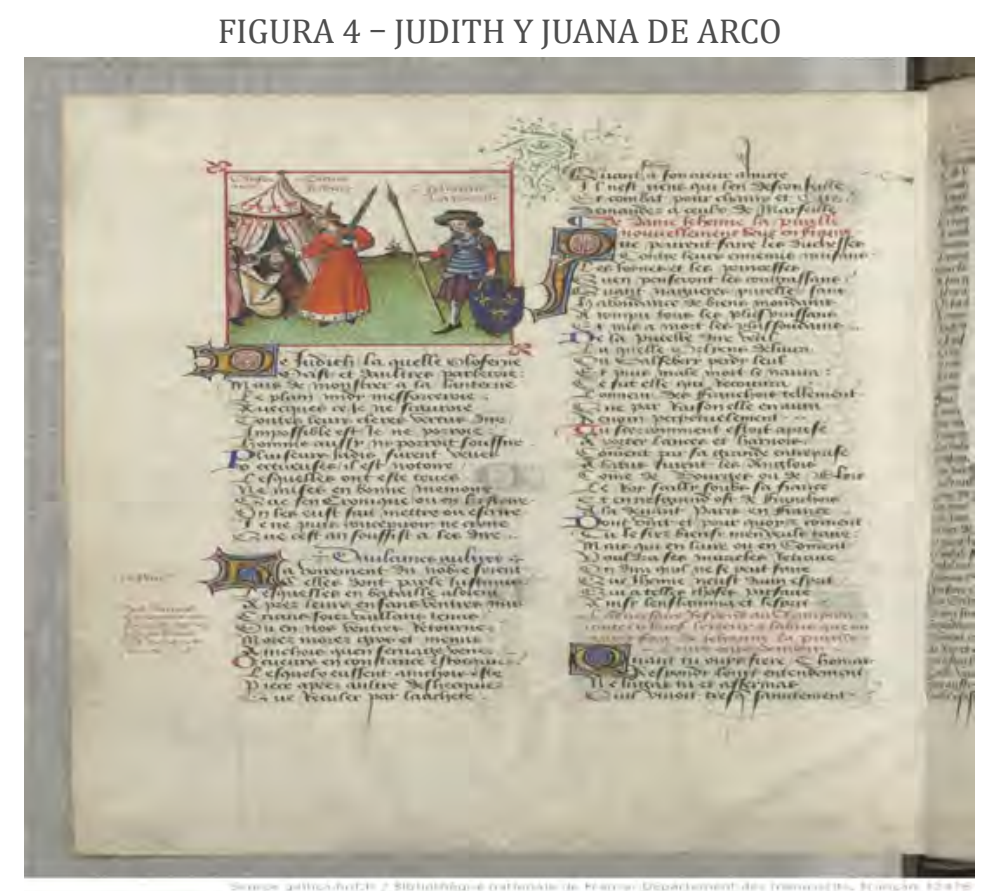

FUENTE: BnF, Ms Français 12476, fol. 101v. Detalle. Disponible en: https://gallica.bnf.fr/ark:/12148/ btv1b525033083/f208.image. Acceso en: 4 abr. 2020. 
Este mismo autor castellano menciona el caso de Pantasilea - recogido igualmente en la obra de Bocaccio -, de la que asegura que

se ovo fecho de las armas tan esforçada, e virtuosa, e varoniblemente que non sólo es de igualar a grandes e esforçador cavalleros, más aun, que pasó a algunos dellos. (LUNA, 1446, cap. XXXVI)

No debe sorprendernos que la vida de Juana de Arco se tradujese al castellano entre 1474 y 1480 - no sin algunas manipulaciones históricas y adaptaciones a la realidad castellana del comento - en una obra dirigida a Isabel I de Castilla, bajo el título La Poncella de Francia. La doncella se presenta a la reina como una mujer fuerte, cristiana, pacificadora y virtuosa (ALCHALABI, 2016, §1 y 7). En definitiva, como un modelo a imitar por una mujer que ostentaba el poder en Castilla y, entre cuyas ricas vestimentas, se ha documentado un cinturón masculino, además de ser, en ocasiones, descrita por las crónicas y relatos de viajeros vistiendo bonete o gorra de hombre (ANGULO, 1951, p. 22).

Juana de Arco pasó los dos últimos años de su vida viviendo, vistiendo y liderando ejércitos como si de un caballero más se tratase. Sin embargo, jamás recurrió al atuendo masculino para ocultar su condición de mujer. Según se indica en el tratado De quadam pueIla (1429), Juana de Arco hizo uso de la indumentaria masculina con fines puramente militares, optando por ropas femeninas al bajarse del caballo, que le hacían recuperar su aspecto naif e inocente (ANSON, 1974, p. 1-32; CRANE, 2002, p. 73-75 y 92-93).

La adopción por parte de Juana de Arco de una indumentaria impropia de su género hizo que, algunos de los hombres que la juzgaron, como Jean d'Estivet, la calificaran de "putana", "femme monstrueuse" o "femme desordonnée et difamée", expresiones que no hacían alusión a su comportamiento sexual, sino a su sexualidad corrupta y deformada. Estos basaban sus acusaciones en textos veterotestamentarios en los que se especifica, con severidad, que "no vestirá la mujer traje de hombre, ni el hombre vestirá ropa de mujer; porque abominación es a Jehová tu Dios cualquiera que esto hace" (Deuteronomio 22,5). De hecho, en las primeras líneas del juicio contra Juana de Arco se recoge la relación de crímenes de los que se le acusaba, entre los que cobra especial protagonismo el uso de prendas masculinas, por ser la transgresión del género una de las acusaciones más evidentes de todas las lanzadas contra la joven (HOBBINS, 2005, p. 21; GRIGAT y CARRIER, 2007, p. 190). Como señala Christine Bard, "la confusión de sexos forma parte de los grandes miedos en Occidente desde la Edad Media” (BARD, 2012, p. 16).

Tan aberrante resultó en época medieval la imagen masculinizada de la joven, quien aseguraba que disponía de licencia divina para vestir prendas masculinas, al igual que para hacer uso de armas en defensa de Dios (CRANE, 1996, p. 300-301; CRANE, 2002, p. 75-76), que los iluminadores medievales optaron por mostrarla vestida siempre acorde a su género, tratando en todo momento de feminizar su imagen, aun cuando lucía armadura. Así la vemos sentada junto a Carlos VII, recibiendo las llaves de Troyes, en los ya citados Vigiles de Charles VII (BnF, ms. Français 5054, fol. 62r) o, incluso, en el dibujo marginal realizado en un registro del parlamento de París del 10 de mayo de 1429, obra de Clément de Fauquembergue (Archives nationales, Registre du Parlement de Paris, 1429), considerada la única 
representación de la Doncella de Orleans realizada en vida de esta que se conserva en la actualidad (figura 5). Una Juana de Arco fuerte y profundamente femenina fue precisamente la que inspiró a John Galliano con motivo de la colección de alta costura otoño/invierno de 2006-2007 de Christian Dior, en la que la imagen de la mística francesa se fundía con toques de film noir y estética cyberpunk, en un claro guiño a Blade Runner (figura 6).

FIGURA 5 - CLÉMENT DE FAUQUEMBERGUE, REPRESENTACIÓN DE JUANA DE ARCO EN EL MARGEN DE UN DOCUMENTO DEL PARLAMENTO DE PARÍS (10 DE MAYO DE 1429)

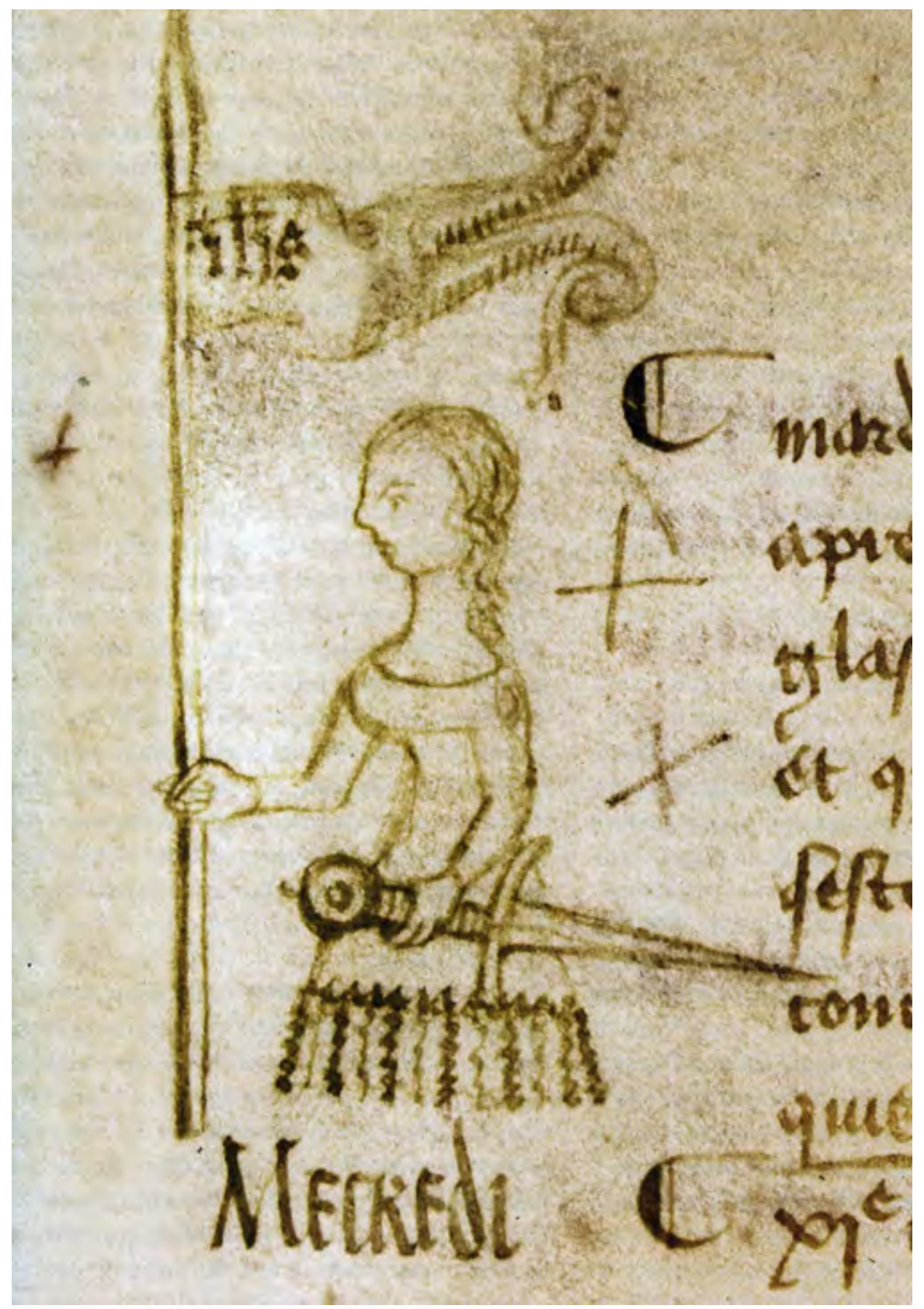

FUENTE: https://upload.wikimedia.org/wikipedia/commons/6/6e/

Contemporaine_afb_jeanne_d_arc.png. Acceso en: 4 abr. 2020. 
FIGURA 6 - COLECCIÓN DE ALTA COSTURA OTOÑO/INVIERNO 2006-2007 DE JOHN GALLIANO PARA CHRISTIAN DIOR

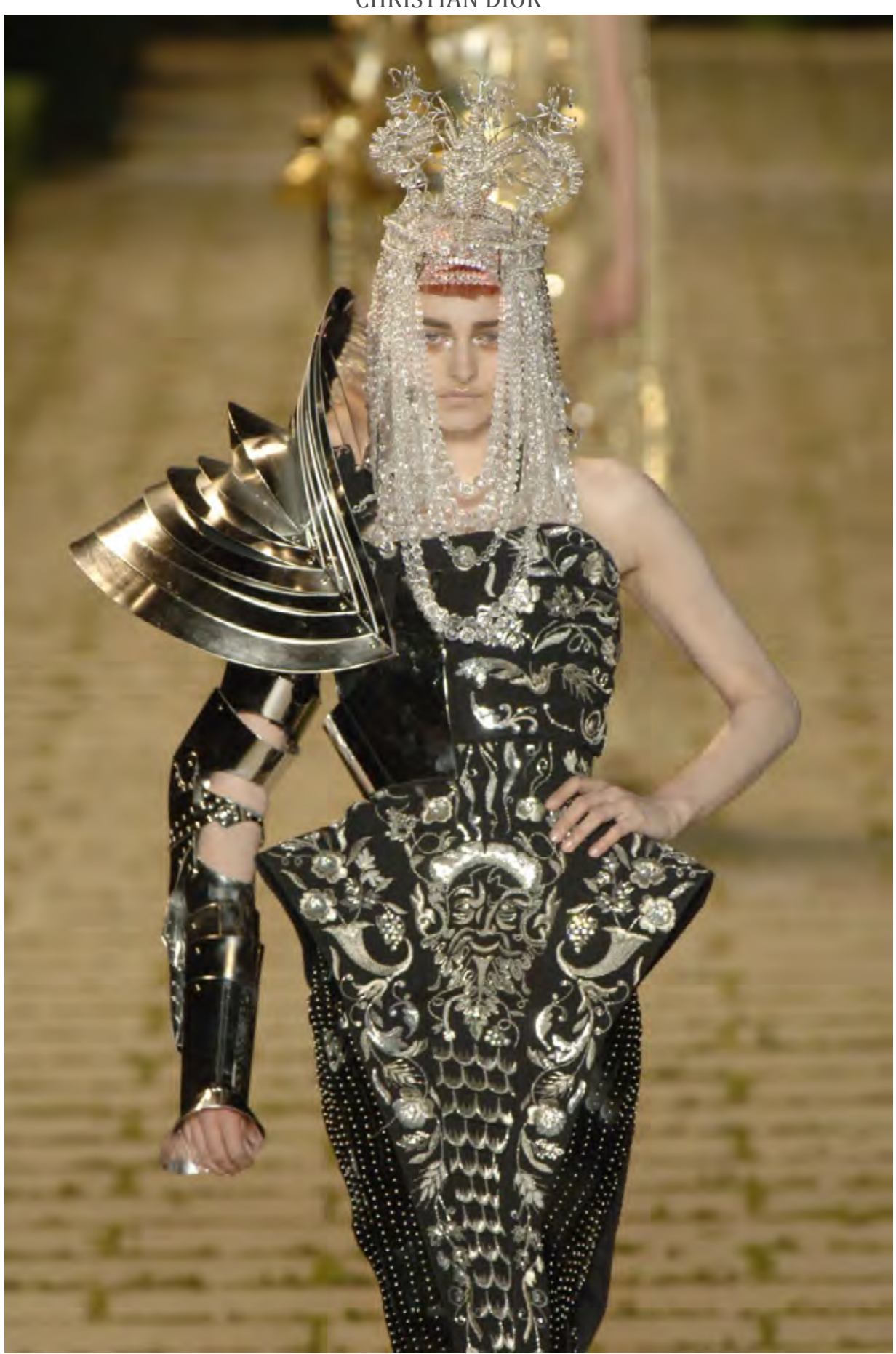

FUENTE: Revista Vogue. Disponible en: https://www.vogue.com/fashion-shows/fall-2006-couture/ christian-dior/slideshow/collection\#1. Acceso en: 04/04/2020 
Ya en el siglo XIX, el mito de Juana de Arco fue recuperado por diversos pintores que optaron por mostrar el lado más heroico de la joven, como fue el caso de Pierre Revoil en su obra Juana de Arco prisionera en Rouen de 1819 conservada en el Museo de Bellas Artes de Rouen, de la Juana de Arco en la hoguera pintada en 1843 por Hermann Stllke (Museo del Hermitage) o de la Juana de Arco en la Coronación de Carlos VII del Museo del Louvre, realizada por Jean-Auguste-Dominique Ingres en 1854, su condición de símbolo de patriotismo tras la guerra franco-prusiana (1870-1871), como vemos en la Juana de Arco de Jules Bastien-Lepage, pintada en 1979 (The Metropolitan Museum of Art) o su faceta más mística, como se aprecia en la Juana de Arco escuchando voces de hacia 1859 de Léon-François Bénouville (Museo de Bellas Artes de Rouen) o la Juana de Arco de John Everett Millais de 1865 (WARNER, 2013, p. 171-257).

Una Juana de Arco que, por esos mismos años, se convirtió en manos de otros artistas en musa y objeto de deseo. Vemos al pintor abrazado a su modelo en El estudio del pintor de Josef Danhauser de 1830, en el Museo de Bellas Artes de Budapest, mientras que Dante Gabriel Rossetti se decantó en 1882 por una Juana de Arco de larga cabellera pelirroja y labios carnosos -afín al ideal de belleza femenino presente en toda la producción del prerrafaelita-, que parece dirigirse a la divinidad mientras apoya la espada sobre su mejilla derecha en un gesto cargado de sensualidad (The Fitzwilliam Museum, Cambridge) (figura 7). Todas estas facetas -fortaleza, misticismo, femineidad, elegancia y sensualidad-, fueron perfectamente combinadas por Donatella Versace en la reinterpretación que hizo del mito de Juana de Arco para la colección de prêt-à-porter otoño/invierno 2012/2013, en la que predominaron los corsés en forma de armadura, las cotas de malla y las cruces.

FIGURA 7 - DANTE GABRIEL ROSSETTI, JUANA DE ARCO, 1882. FITZWILLIAM MUSEUM, CAMBRIDGE

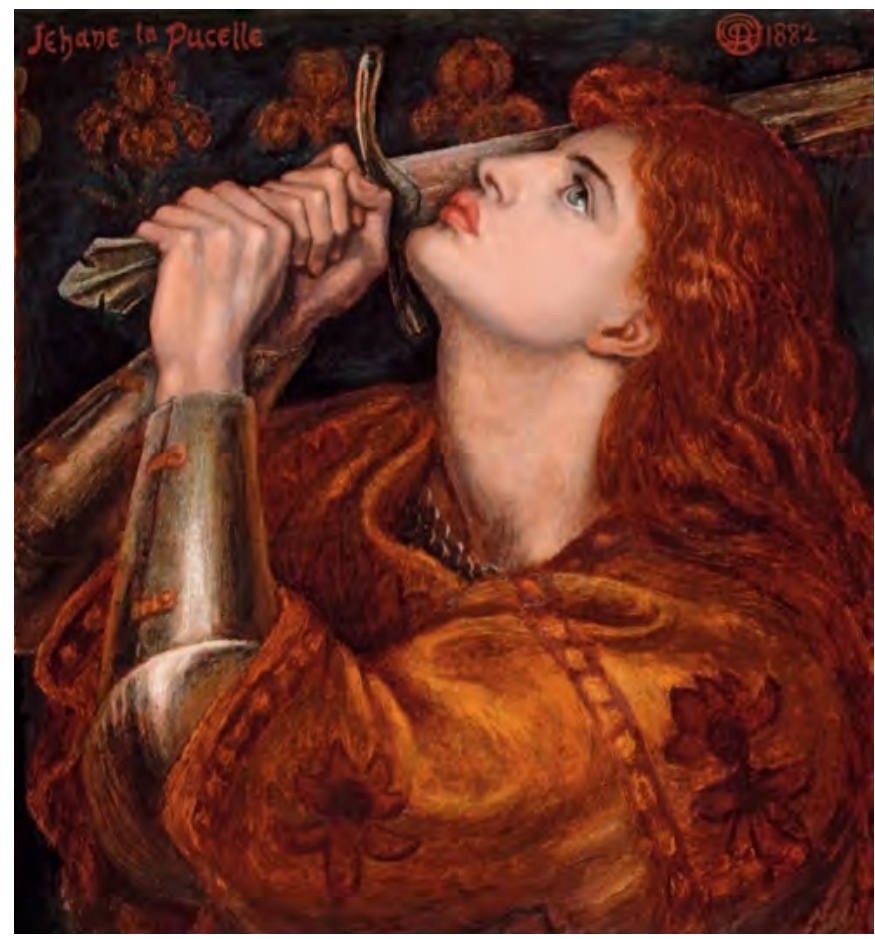

FUENTE: https://upload.wikimedia.org/wikipedia/commons/d/d3/Dante_Gabriel_Rossetti_-_Joan_of_ Arc_\%281882\%29.jpg. Acceso en: 4 abr. 2020. 
"Lo que cien mil hombres no fueron capaces de hacer": fortaleza femenina y cross-dressing

En su ya citado Ditié, Christine de Pizan recurrió a la figura de Juana de Arco para exaltar la grandeza y virtuosidad del género femenino, y demostrar que, en ocasiones, este es capaz de superar en grandeza y heroísmo al masculino. No debemos olvidar que Christine de Pizan estructuró su composición en sesenta y una estrofas de versos octosílabos, propias de los cantares de gesta, destinados a narrar hazañas masculinas, las cuales quedaron, en esta ocasión, eclipsadas por completo por la figura de la doncella:

\author{
¡Oh! ¡Qué honor al femenino \\ sexo! Que Dios la ama aquí se percibe, \\ Cuando de todo ese gran pueblo dañino, \\ Por el que todo el reino está desierto, \\ Por una mujer está a salvo y recuperado, \\ Lo que cien mil hombres no fueron capaces \\ de hacer. \\ (PIZAN, 1429, XXXIV)
}

En definitiva, "una luchadora que domina a los hombres de manera asombrosa", palabras con las que Paco Rabanne define a su musa medieval, protagonista de su Colección Manifiesto 12 Vestidos imposibles de llevar fabricados en materiales contemporáneos, presentada el 1 de febrero de 1966 en el hotel George V. Primaron los discos y placas de rhodoid que daban forma a armaduras de acetato de celulosa que envolvían el cuerpo de las modelos (figuras 8 y 9). La Juana de Arco de Rabanne era una mujer socialmente reivindicativa, a la que dio vida la mítica Donyale Luna, la primera supermodelo negra y la primera afroamericana que ocupó la portada de la edición británica de la revista Vogue.

FIGURAS 8 Y 9 - COLECCIÓN MANIFIESTO DE PACO RABANNE (1966)

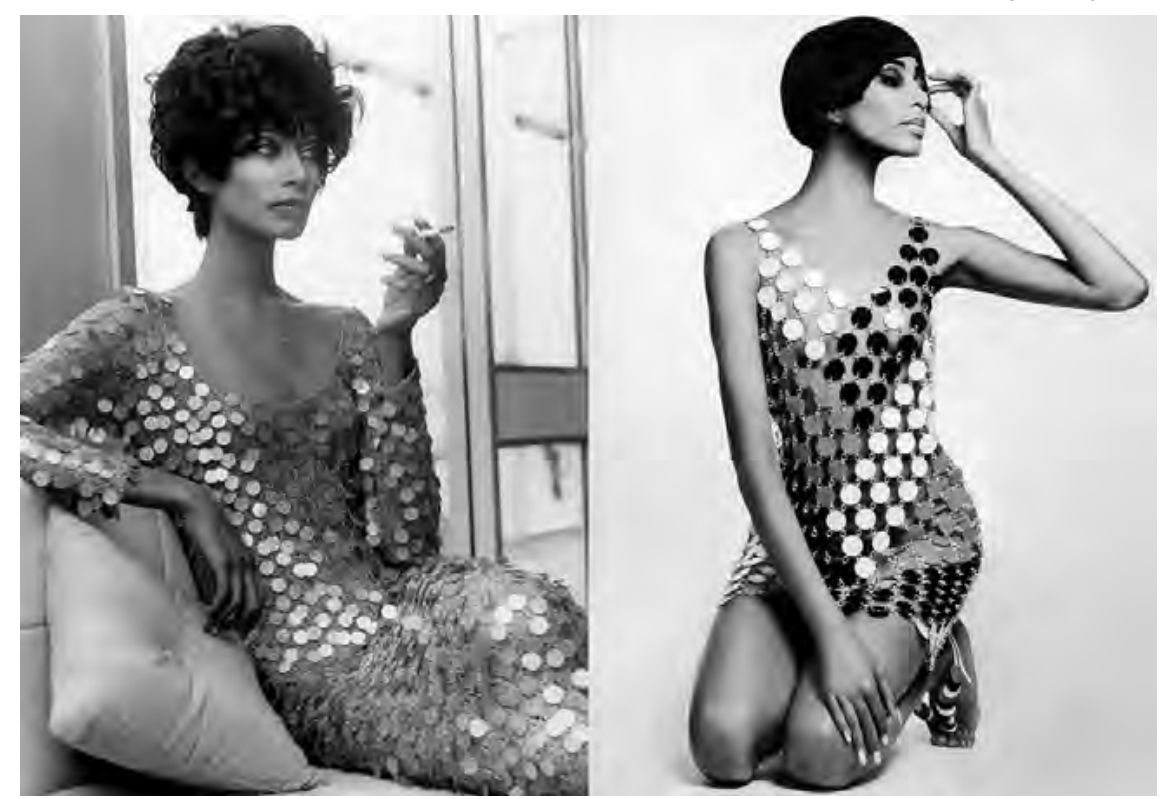

FUENTE: http://vein.es/wp-content/uploads/2018/02/RABANNE-02-B.jpg. Acceso en: 4 abr. 2020. 
Desde entonces, la figura de Juana de Arco ha sido una constante en la producción de Paco Rabanne. Con motivo de la colección otoño/invierno de 2018-2019, Julien Dossena recuperó el imaginario de las primeras colecciones del diseñador vasco, volviendo a las cotas de malla, a las que dotó de un cierto aire futurista (figura 10). Referencias que han vuelto a estar presentes en la colección otoño-invierno de 2020-2021, en la que se combinan cotas de malla, imitaciones de piel, tapices de lentejuelas, jerséis ceñidos, estampados anacrónicos y prendas de estilo religioso. Todo ello envuelto en una estética que parte de la mítica Juana de Arco y culmina en el universo grunge (figura 11). Como señala Dossena, se trata, ante todo, de una colección cargada de espiritualidad y simbolismo en plena era tecnológica:

No quiero decir que sean un culto, exactamente. No soy en absoluto creyente, pero estoy interesado en cómo pensar en algo que está más allá aún mueve a todo el mundo, incluso en la era de la tecnología 5 .

(MOWER, 2020, https://www.vogue.com/fashion-shows/fall-2020-ready-towear/paco-rabanne. Acceso: 15 abr. 2020)

\section{FIGURA 10 - COLECCIÓN OTOÑO/INVIERNO DE 2018-2019 DE PACO RABANNE}

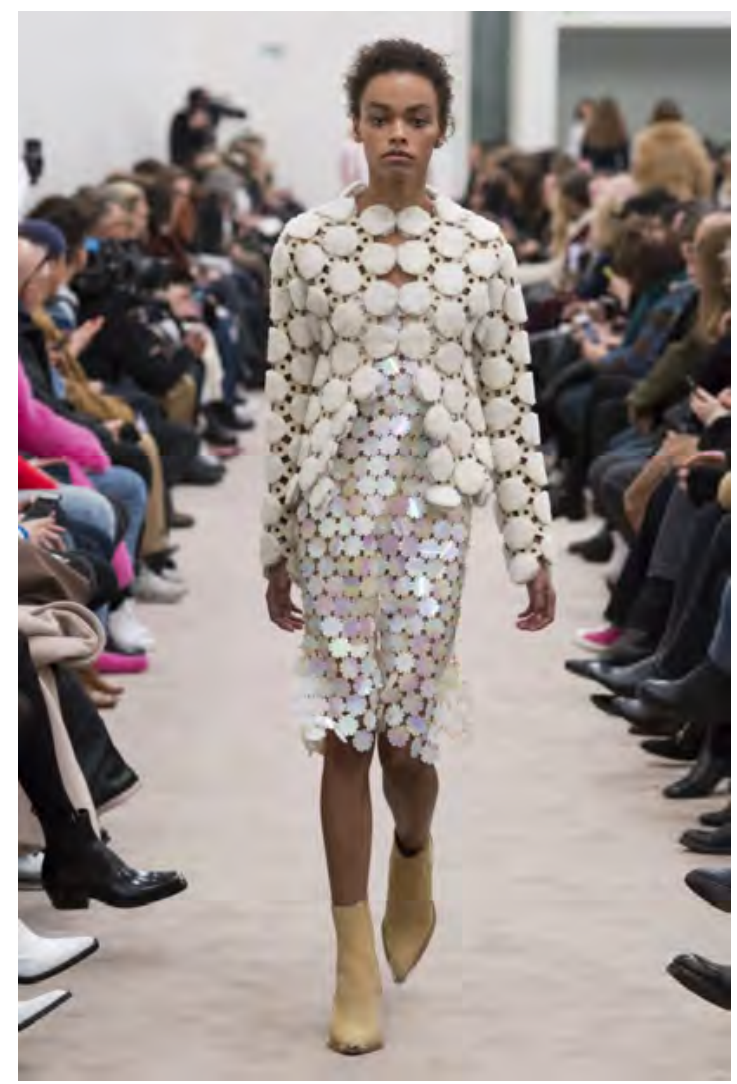

FUENTE: Revista Vogue. Disponible en: https://www.vogue.es/pasarelas/otono-invierno-2018-2019-preta-porter/paco-rabanne/slideshow/collection/34. Acceso en: 4 abr. 2020.

\footnotetext{
5 Tradução nossa para: "I don't want to say that they're a cult. I'm not a beliver at all, but I'm interested in how thinking about something that's beyond still drives everyone, even in the age of technology".
} 


\section{FIGURA 11 - COLECCIÓN OTOÑO/INVIERNO DE 2020-2021 DE PACO RABANNE}

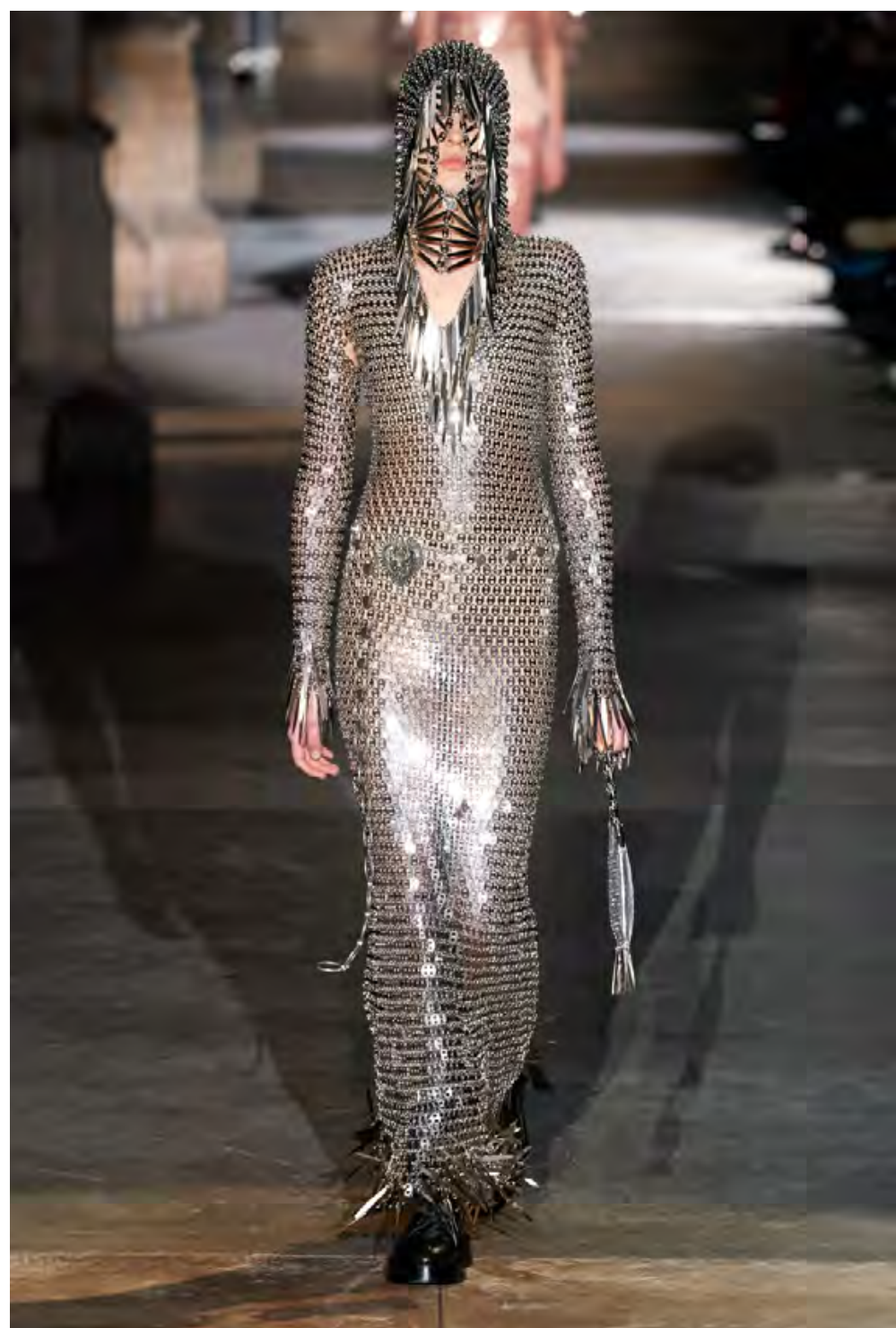

FUENTE: Revista Vogue. Disponible en: https://www.vogue.com/fashion-shows/fall-2020-ready-to-wear/ paco-rabanne/slideshow/collection\#12. Acceso en: 4 abr. 2020.

Una versión más oscura y siniestra de Juana de Arco sirvió de inspiración a Alexander McQueen, quien quería empoderar a la mujer, blindar y hacer invulnerable el cuerpo de la mujer, a cualquier tipo de ataque externo, llegando a infligir temor a su alrededor ("I want to empower women. I want people to be afraid of the women I dress") y comparaba su forma de cubrir el cuerpo de la mujer con el hecho de dotarlas de una armadura (BOLTON, 2011, p. 60). Precisamente, encontramos armaduras en su colección de otoño/invierno de 1998-1999, presentada en febrero en el Gatliff Road Warehouse de Londres y que llevó por título Joan (BOLTON, 2011, p. 206). El propio Alexander McQueen afirmó que jamás obtuvo su inspiración de mujeres concretas, sino que solía buscar a sus musas entre las mujeres icónicas del pasado: 
En realidad, no me inspiro en mujeres concretas...Sino más bien en las mentes de las mujeres del pasado, como Catalina la Grande, o María Antonieta. Personas que fueron condenadas. Juana de Arco o Coleta. Mujeres icónicas ${ }^{6}$.

(BOLTON, 2012, p. 115)

El diseñador británico dedicó el show a su amiga y musa Annabelle Neilson. Los cabellos platino, las trenzas sobre cabezas aparentemente afeitadas y los flequillos rectos corrieron a cargo de Guido Paulo. Estos se complementaron con lentes de contacto rojas, como guiño a Los niños del maíz (1960). El rojo fue uno de los grandes protagonistas de esta colección, que presenta, a su vez, una clara deuda con el Robot Couture de Thierry Mugler (alta costura otoño/invierno 1995-1996) (figura 12). Rojo es también el color elegido por el miniaturista de Les Vigiles de Charles VII para vestir a Juana en la hoguera (BnF, ms. Français 5054, fol. 71r) (figura 13).

\section{FIGURA 12 - COLECCIÓN DE ALTA COSTURA OTOÑO/INVIERNO 1995-1996 DE MUGLER}

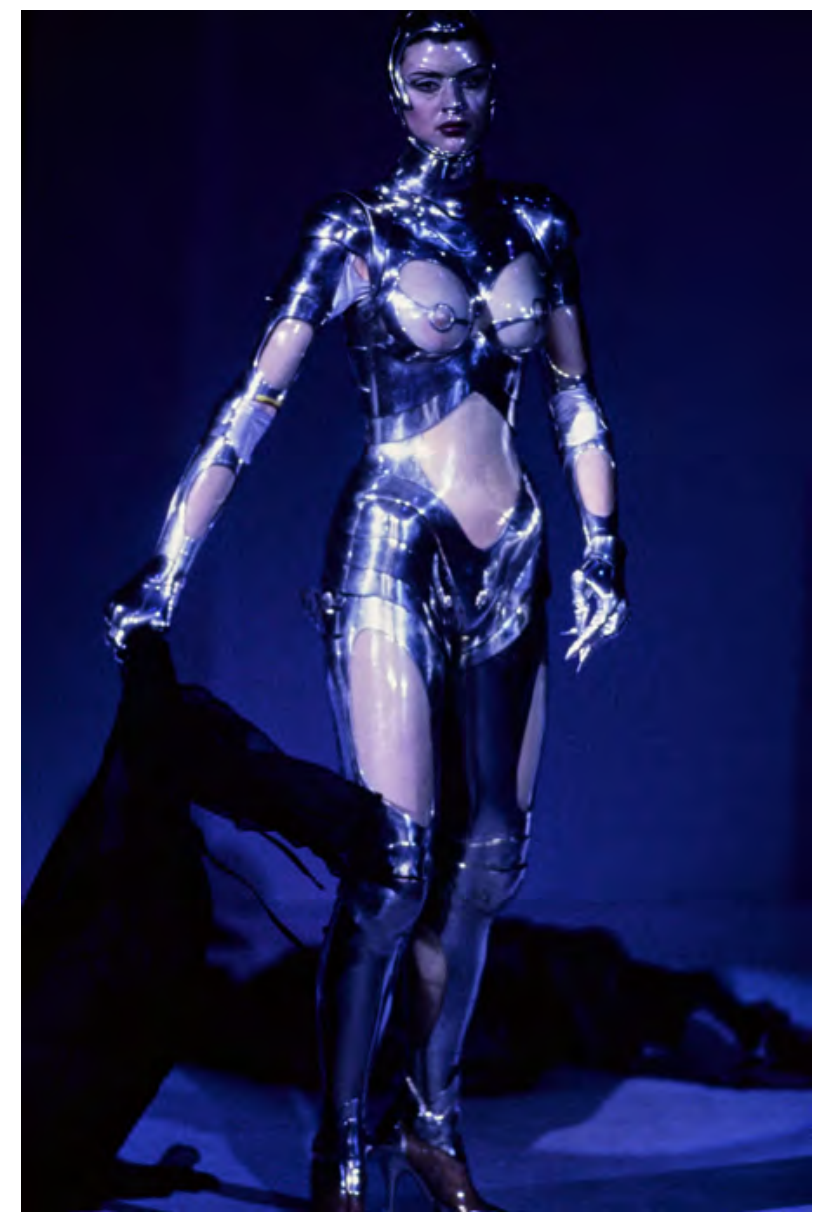

FUENTE: Revista Vogue. Disponible en: https://www.vogue.com/fashion-shows/fall-1995-couture/ mugler/slideshow/collection. Acceso en: 4 abr. 2020.

\footnotetext{
${ }^{6}$ Tradução nossa para: "I don't really get inspired [by specific women]... It's more in the minds of the women in the past, like Catharine the Great, or Marie Antoinette. People who were doomed. Joan of Arc or Colette. Iconic women".
} 


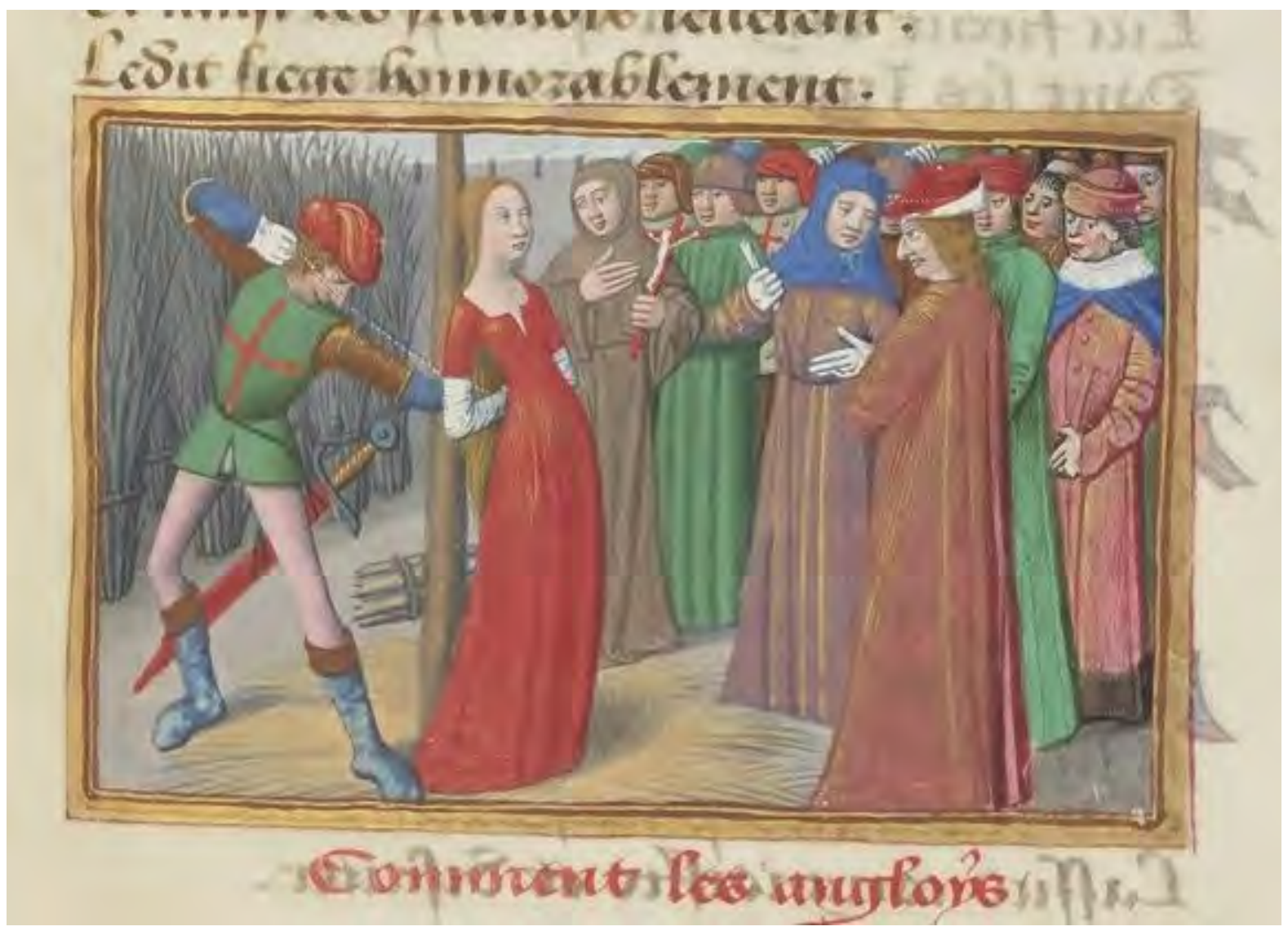

FUENTE: BnF, mS. Français 5054, fol. 71r. Detalle. Disponible en:

https://gallica.bnf.fr/ark:/12148/btv1b105380390/f153.image. Acceso en: 4 abr. 2020.

El show culminó con una Juana de Arco con el rostro cubierto, envuelta por un círculo de fuego (figura 14), que volvemos a ver en el vídeo-homenaje To Lee, With Love, Nick (2010) del fotógrafo Nick Knight, con música de Björk. Las palabras de Diana Ross, reproducidas como cierre del desfile, tomadas de su tema Remember Me del álbum Diana! de 1971, aportaban un ligero toque esperanzador: "You're gonna make it, you're gonna make it”, (KNOX, 2010, p. 24-25; BOLTON, 2012, p. 21-22). 


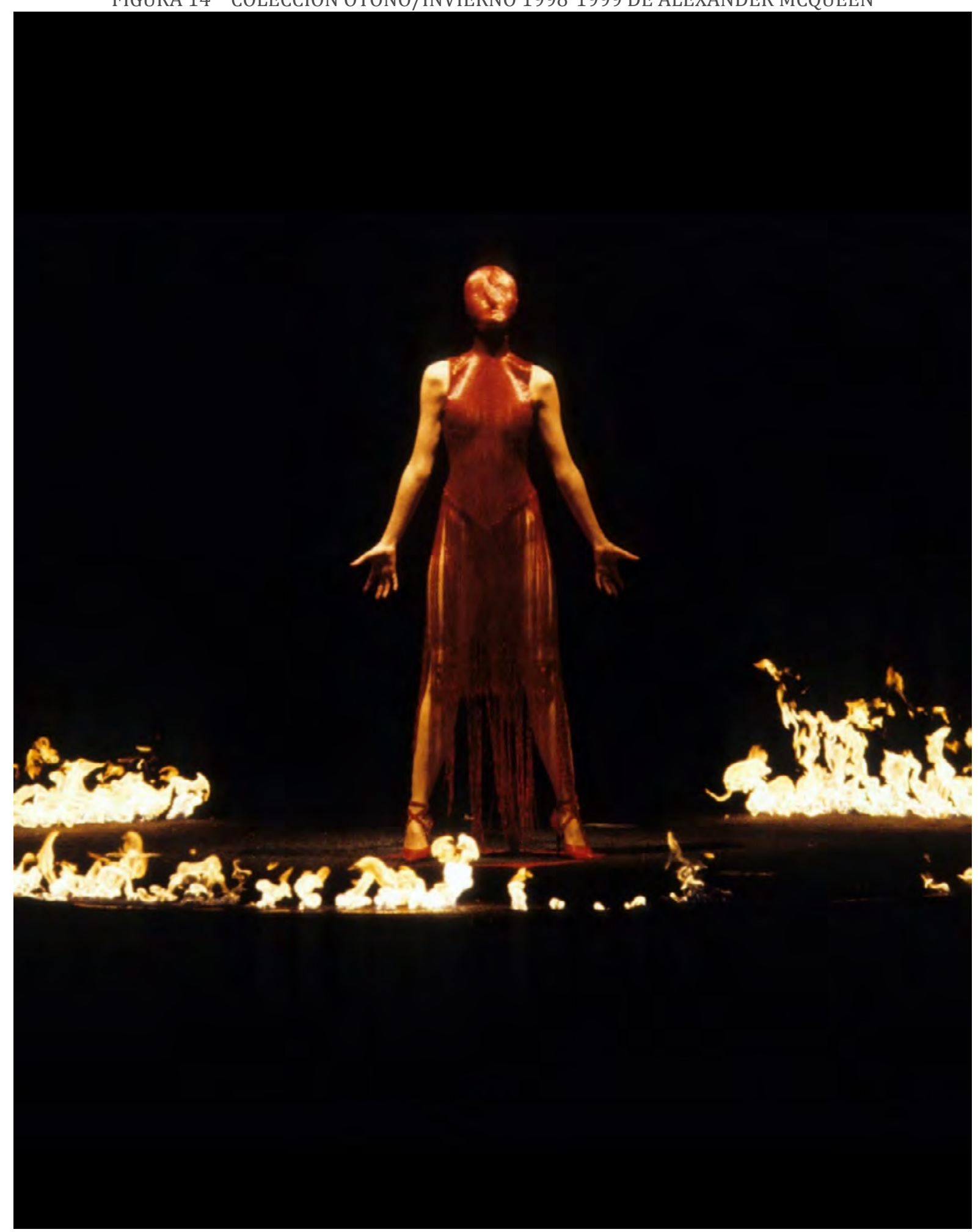

FUENTE: Revista Vogue. Disponible en: https://www.vogue.com/fashion-shows/fall-1998-ready-to-wear/ alexander-mcqueen/slideshow/collection\#83. Acceso en: 4 abr. 2020. 
La colección Joan será también recordada por el momento en el que Lady Gaga, vestida con uno de los diseños de McQueen y la cara cubierta por el tupido encaje rojo, recogió, de manos de Eminem, uno de sus galardones en la gala de los MTV Music Video Awards de 2009, así como por el hecho de que uno de sus looks abrió la exposición retrospectiva Alexander McQueen. Savage Beauty, comisariada en 2010 por Andrew Bolton (The Metropolitan Museum of Art).

McQueen retomó la figura de Juana de Arco en su colección otoño-invierno 2009, en la que combinó la cota de malla, que cubría el rostro y tapaba la boca de la modelo, con un ajustado vestido de corte sirena. Rígidas estructuras a modo de armadura, que, en ocasiones, llegan a ocultar parcialmente el rostro, cubren, una vez más, el cuerpo femenino en las colecciones It's Only a Game (primavera/verano 2005) y In Memory of Elizabeth How, Salem 1692 (otoño/ invierno 2007-2008) (BOLTON, 2011, p. 206-207y 210), así como en la colección de alta costura que el diseñador británico realizó como director creativo de Givenchy y que llevó por título The Search of the Golden Fleece (primavera/verano 1997) (BOLTON, 2011, p. 211) (figura 15).

\section{FIGURA 15 - COLECCIÓN THE SEARCH OF THE GOLDEN FLEECE (PRIMAVERA/VERANO 1997) DE ALEXANDER MCQUEEN PARA GIVENCHY}

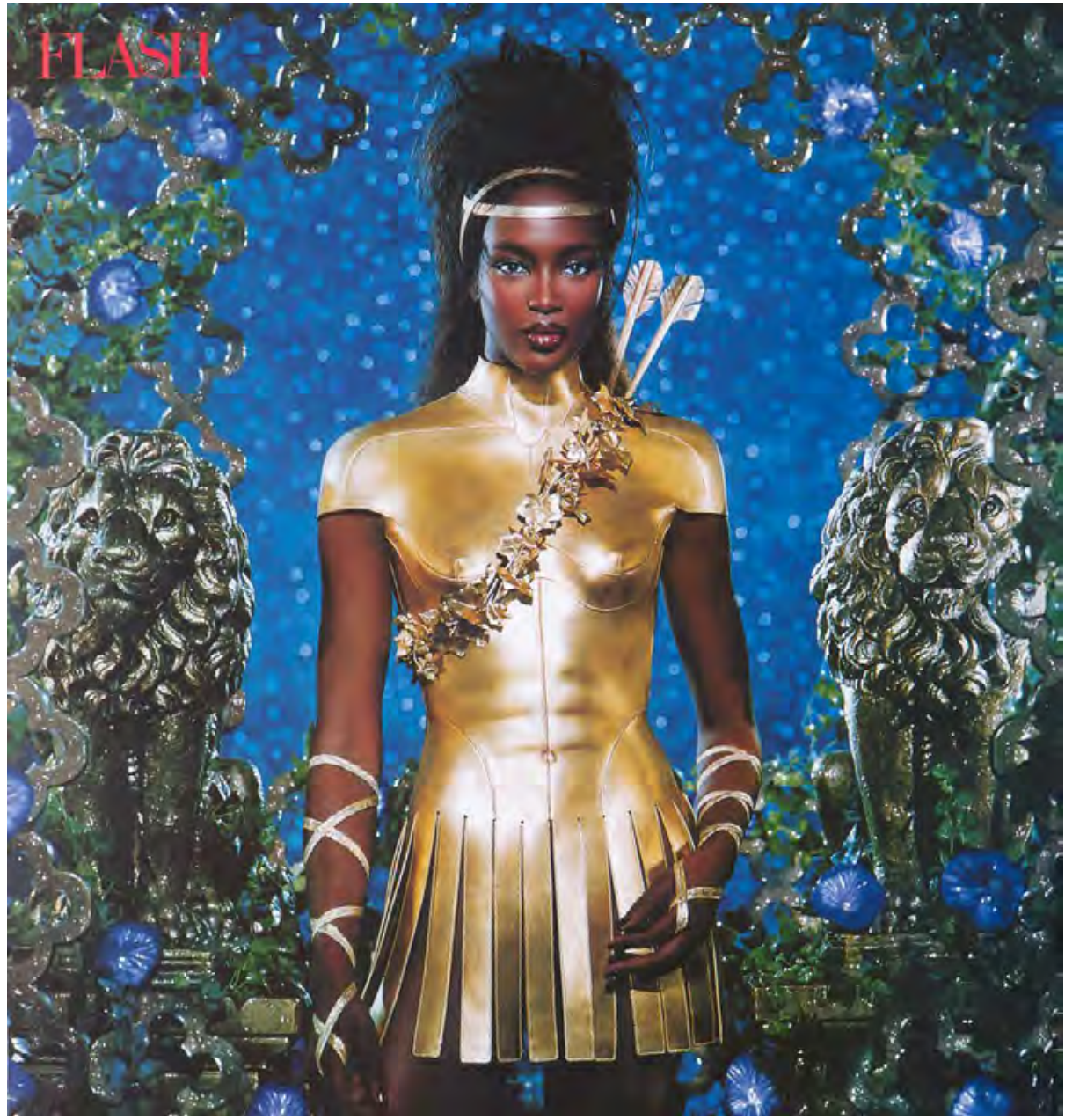

FUENTE: https://www.pinterest.co.uk/pin/183521753547088286/. Acceso en: 4 abr. 2020. 
A finales de la Edad Media, Juana de Arco se alzó como la depositaria del legado de aquellas mujeres santas que hicieron uso del cross-dressing como un instrumento para proteger su virginidad, como, por ejemplo, Eugenia, Christina de Markyate, Natalia, Marina, Theodora, santa Margarita o santa Tecla (FRAIOLI, 1981, p. 813-814). A pesar de que, como se ha indicado más arriba, jamás hizo uso de la indumentaria militar para ocultar su condición de mujer, sí que sabemos que, durante su prisión y juicio, Juana de Arco se negó a abandonar su vestimenta masculina (ANSON, 1974, p. 1-32; CRANE, 1996, p. 297, BRASILLACH, 1998, p. 35, 49-50, 67, 72, 83, 94-95, 97, 102-03, 110-111, 114, 121, 127, 133-134 y 136). Postura que, con motivo de la revisión del proceso de la doncella llevado a cabo en el Antiguo Régimen -periodo histórico durante el cual el travestismo se consideró un "delito de falsedad" y, por lo tanto, grave-, se justificó asegurando que la joven volvió a vestir ropa contraria a su sexo tras haber sido víctima de una violación durante su cautiverio (BARD, 2012, p. 16).

Décadas más tarde, al igual que Juana de Arco, más mujeres reclamaron su autoridad social por medio de la adopción y uso de prendas propias del género masculino. Incluso, algunas humanistas criticaron el adorno femenino, al considerarlo enemigo del saber. Laura Cereta, en su carta Maldición contra la ornamentación de las mujeres, redactada en 1487 y dirigida a Augustinus Aemilius, aseguraba preocuparse más “por las letras que por los vestidos ostentosos". Afirmaba, que, si Marco Antonio se sintió atraído por la enjoyada Cleopatra, ella se decantaba por imitar la inocencia de Rebeca; si Paris deseaba a la hermosa Elena, ella prefería la modestia de Raquel. Cereta criticó duramente a las mujeres que trataban de ocultar su verdadero físico tras múltiples capas de maquillaje, prendas ajustadas que aumentaban el pecho, o tacones. Aseguraba que estas deberían apostar por el adorno del honor y no de la vulgaridad, llegando a afirmar que aquellas mujeres que, aun nacidas libres, optaban por adornarse, no hacían sino enorgullecerse "de estar cautivas" (KING y RABIL, 1992, p. 77-80; VARGAS, 2016, p. 265). Esclavitud a la que volverá a remitir siglos más tarde Concepción Arenal al declarar que

otro inconveniente de no levantar el espíritu de la mujer á las cosas grandes es hacerla esclava de las pequeñas. Las minuciosidades inútiles y enojosas, los caprichos, la idolatría por la moda, la vanidad pueril, todo esto viene de que su actividad, su amor propio, tiene que colocarse donde puede y hallando cerrados los caminos que conducen á altos fines, desciende por senderos tortuosos a perderse en un intrincado laberinto. Las necesidades verdaderas, según la clase de cada uno, tienen límites, no los hay para las del capricho y la imaginación, que pide al lujo goces acaso incompatibles con la honra. La mujer se hace esclava del figurín y de la modista, cifrando su bienestar en la elegancia y en la riqueza de su traje, y en que la casa esté lujosamente amueblada. Hay pocas disposiciones de nuestro espíritu con tendencias tan invasoras como la vanidad: se desborda si no se le pone coto. (ARENAL, 1869, p. 51-52) 
En plena Revolución, Théroigne de Méricourt adoptó el traje "a la amazona" para "tener el aspecto de un hombre y huir así de la humillación de ser una mujer". Si bien las denominadas "amazonas de la Revolución" no vestían pantalón, sí que lucían sombrero, en lugar de la habitual cofia, y una blusa ceñida, considerada entonces propia del sexo opuesto, decorada con trencillas que recuerdan a los galones, y pechera de encaje (BARD, 2012, p. 47-48). Poco después, el 7 de noviembre de 1800, una ordenanza de la jefatura de policía de París prohibió a las mujeres el uso de prendas masculinas:

Toda mujer encontrada travestida que no siga las disposiciones de los artículos procedentes será detenida y conducida a la jefatura de policía. (BARD, 2012, p. 63-64)

El "traje de amazona" fue recuperado años más tarde con motivo de las barricadas de 1830. Si bien en las estampas conservadas de la época se representa a las combatientes con vestido, los relatos posteriores que reconstruyen lo sucedido insisten en la participación de mujeres jóvenes fuertemente armadas y vestidas de hombre (BARD, 2012, p. 127).

\section{El legado de Juana de Arco: virilización de la mujer, estética andrógina y Power Dressing}

El legado de estas mujeres, encabezadas por Juana de Arco, pioneras en la transgresión de los límites del género por medio del uso de prendas masculinas, es extenso y variado a lo largo de la historia de la indumentaria, y un tema de continua actualidad en el ámbito de la moda. A pesar de que, en la segunda mitad del siglo XIX, en ciudades como San Francisco, las mujeres -y también los hombres-, fueron arrestados por practicar el cross-dressing (práctica criminalizada en 1863), a lo largo del siglo XX fueron numerosos los ejemplos de mujeres que se enfundaron, de nuevo, en prendas propias del sexo opuesto para burlar las limitaciones sociales impuestas (SEARS, 2015, p. 2 y 42). Durante la Segunda Guerra Mundial, la cartelería de propaganda se vio invadida por figuras de mujeres trabajadoras, claramente masculinizadas, como se puede apreciar en el emblemático cartel de Rosie the Riveter realizado por J. Howard Miller en 1943 para la compañía Westinghouse Electric (figura 16). A pesar de que esta misma imagen fue recuperada por el movimiento feminista en la década de 1980, en origen, fue, en realidad, concebida para aumentar la productividad de las trabajadoras de la mencionada compañía. 
FIGURA 16 - J. HOWARD MILLER, ROSIE THE RIVETER, 1943

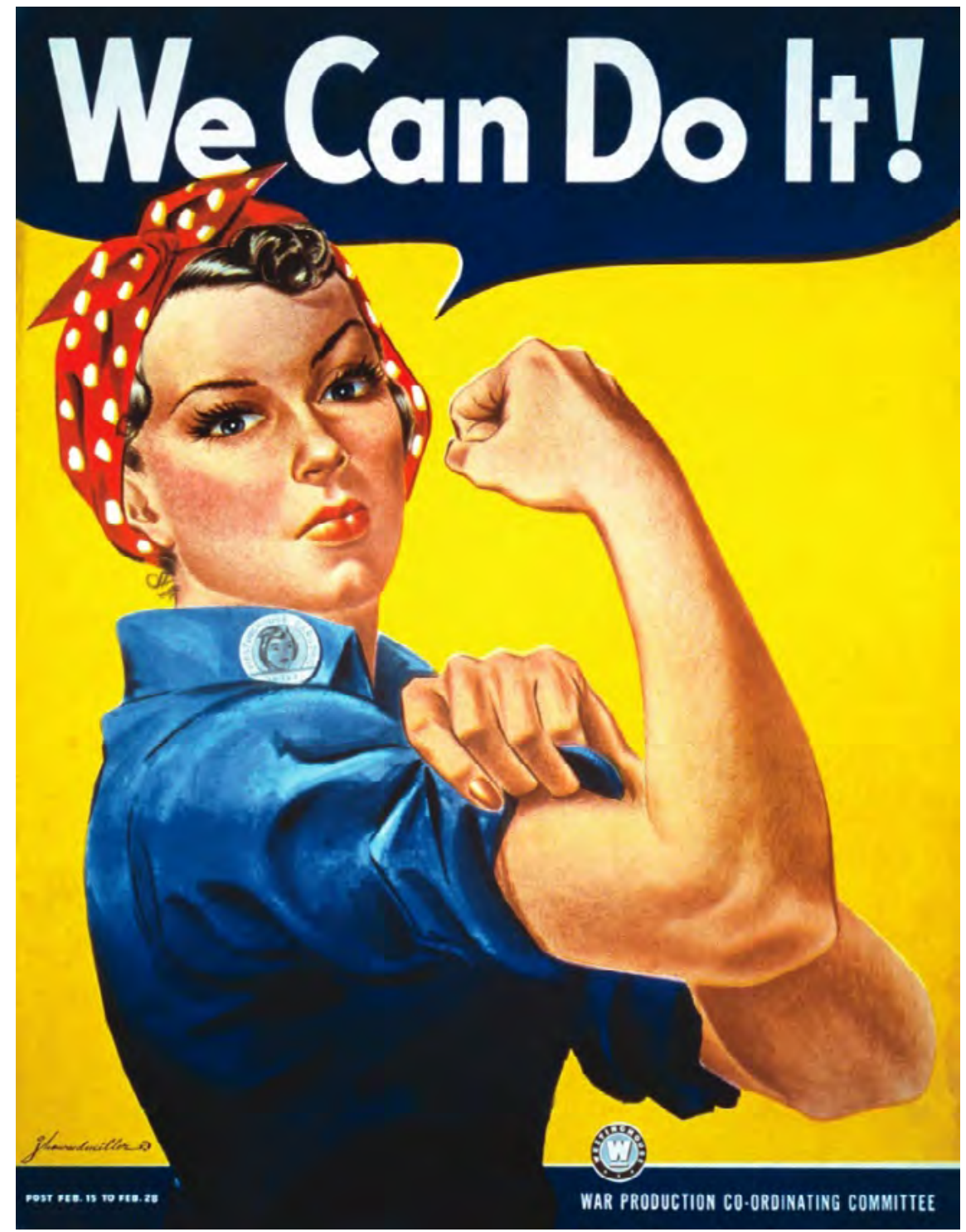

FUENTE: https://es.wikipedia.org/wiki/Rosie_the_Riveter\#/media/ Archivo:We_Can_Do_It!.jpg. Acceso en: 4 abr. 2020.

El cartel estaba inspirado en un cuadro de Norman Rockwell que mostraba a una joven pelirroja, vestida con un mono de trabajo, que sostenía una pistola remachadora, mientras se comía un sándwich sacado de una tartera marcada con su nombre, Rosie, sobre un fondo estampado con una ondeante bandera de los Estados Unidos. La fama de la obra se vio considerablemente incrementada al ser seleccionada para ocupar la portada de la edición del 29 de mayo de 1943 del Saturday Evening Post. La labor llevada a cabo por la prensa y, muy especialmente, por las revistas, resultó fundamental en el proceso de "glamurización" de los trabajos hasta entonces realizados por hombres. Estas lograron convencer a muchas 
mujeres de que su trabajo no solo respondía a una necesidad económica, sino también a un gesto de amor y patriotismo (MASSCHELEIN, 2012, p. 3). Espíritu que se ve recogido, asimismo, en algunos slogans publicitarios como el "Heroines...USA" de Kraft o el "You're a good soldier, Mrs. America" de un anuncio de aspiradoras (MASSCHELEIN, 2012, p. 5).

A finales del siglo XIX la indumentaria comenzó a adaptarse a los crecientes deseos de libertad que fueron despertando entre las mujeres. Mujeres que comenzaron a realizar actividades hoy en día tan cotidianas como montar en bicicleta, pero que hasta entonces habían sido consideradas impropias de su género. Especialmente interesante resultan en este sentido las declaraciones de Ada Earland (1893) en relación a la reforma llevada a cabo por aquellos años en la indumentaria femenina:

\begin{abstract}
Los hombres jamás podrán entender, salvo si lo experimentan ellos mismos, que una mujer sobre ruedas está limitada por su falda. Incluso sin viento, la pérdida de impulso por la fricción es inmensa, y, con ello, el placer de montar en bici se transforma a menudo en miseria. El esfuerzo extra requerido para propulsar la máquina, cuando tu falda está actuando como una vela que te hace retroceder, es ya lo suficientemente malo, incluso sin ser consciente del aspecto desarreglado y poco atractivo ${ }^{7}$.
\end{abstract}

(JUNGNICKEL, 2018, p. 55)

Al igual que Juana de Arco se deshizo de sus prendas de mujer al adentrarse en el campo de batalla, por considerarlas impropias para este, a finales del siglo XIX, las mujeres empezaron a renegar de la falda, alegando que limitaba considerablemente su libertad de movimiento. Aunque en un primer momento fueron los fabricantes de bicicletas los que se preocuparon por adaptar el producto a sus nuevas clientas, fue finalmente la reforma de la moda femenina - marcada, entre otros hitos, por la fundación de la Rational Dress Society en Londres en 1881 -, la que logró dar respuesta a la situación. Una solución no exenta de polémica. Figuras como la ciclista Tessi Reynolds se alzaron entonces como férreas defensoras del rational dress (EDWARDS, 2017, p. 96; JUNGNICKEL, 2018, p. 56-60 y 64-75). Este recordaba al atuendo promovido años atrás, en 1851, por Amelia Jenks Bloomer, editora de The Lily - un periódico creado por y para mujeres -, conformado por una falda de tela ligera, a la altura de la rodilla, sobre unos pantalones bombachos (CHRISP, 2005, p. 14; BARD, 2012, p. 98-105; COLE y DEIHL, 2015, p. 42-43; HORAK, 2016, p. 5; EDWARDS, 2017, p. 82). Prenda que se impregnó de exotismo en las primeras décadas del siglo XX de manos de Paul Poiret, impulsor de los denominados harem pants. Años más tarde, en 1931 la tenista Lilí Álvarez hizo su aparición en el Roland Garros de París luciendo la falda-pantalón diseñada por Elsa Schiaparelli (BREWARD, 2003, p. 39; COLE y DEIHL, 2015, p. 109; BARD, 2012, p. 179-183, ENGLISH, 2013, p. 23; EDWARDS, 2017, p. 118) (figura 17).

\footnotetext{
Tradução nossa para: "Men can never know, unless they try the experiment themselves, how heavily a wheelwoman is handicapped by her skirt. Even without wind the loss of power through friction is immense, while with it the pleasure of riding is often changed to misery. The extra exertion required to propel the machine, when your skirt is acting as a sail to blow you back, is bad enough even without the consciousness of looking untidy and ungraceful".
} 


\section{FIGURA 17 - LILÍ ÁLVAREZ CON LA FALDA-PANTALÓN DISEÑADA POR ELSA SCHIAPARELLI}

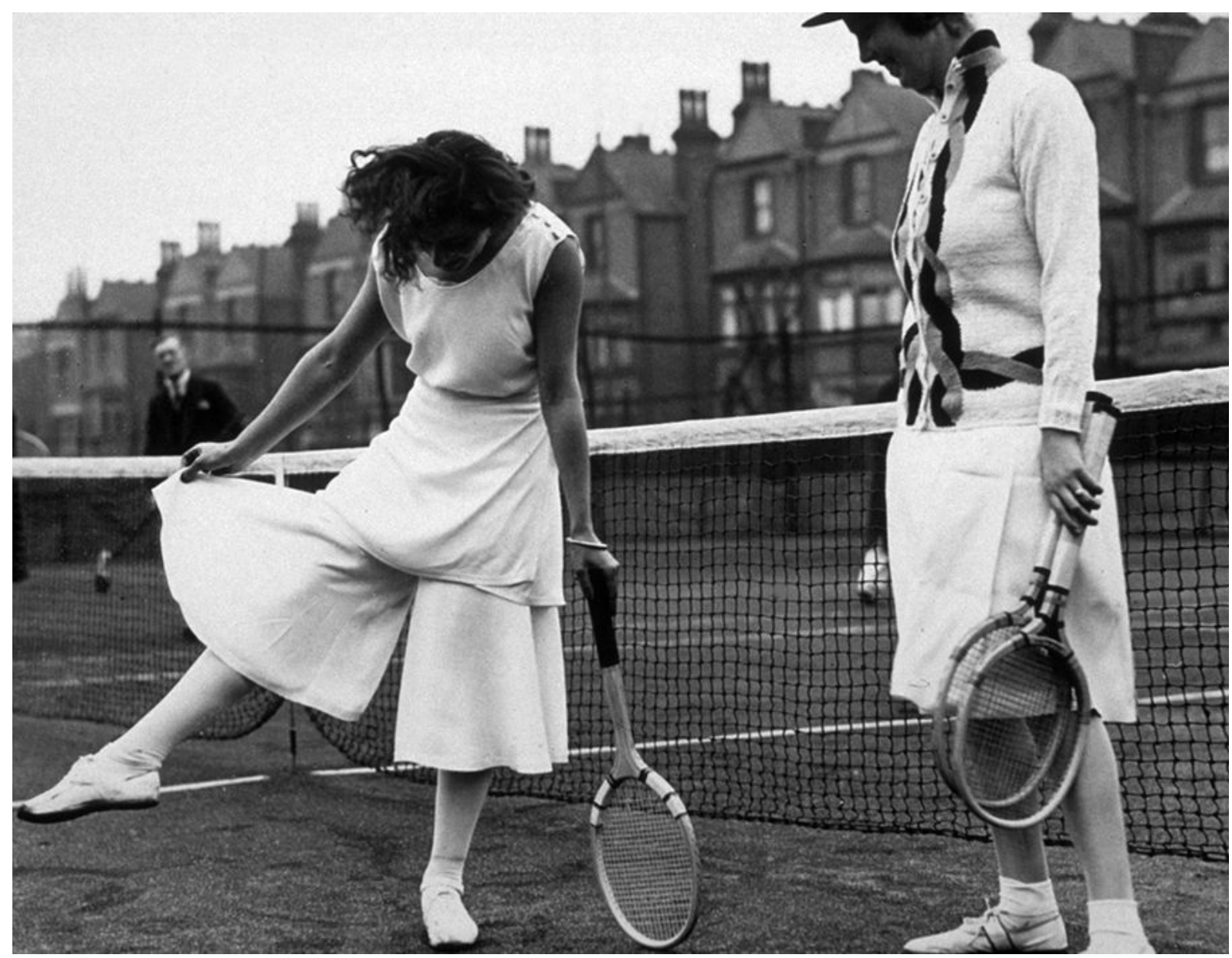

FUENTE: https://www.pinterest.com.mx/pin/308074430752287306/. Acceso en: 4 abr. 2020.

Parece que los pantalones habían llegado para quedarse en los armarios de todas aquellas mujeres que hicieron de la moda una nota fundamental de su canto de libertad. Entre ellas destacan, por ejemplo, la escritora George Sand, "figura principal cuando se habla de la virilización de las mujeres, tanto si se trata del pantalón como del cigarro" (BARD, 2012, p. 137), las pintoras Rose Bonheur y Louise Abbéma, la actriz Sarah Bernhardt, la deportista Violette Morris o la aviadora desaparecida en el océano Pacífico, Amelia Earhart (1897-1937) (BARD, 2012, p. 127, 137-151, 172 y 205-227). Mención especial merece el caso de la arqueóloga Jane Dieulafoy (1851-1916), quien aseguraba que compraba trajes a medida para aprovechar el tiempo que ahorraba así y poder trabajar más. Al igual que Juana de Arco, Dieulafoy se decantó por el cabello corto (figura 18). 


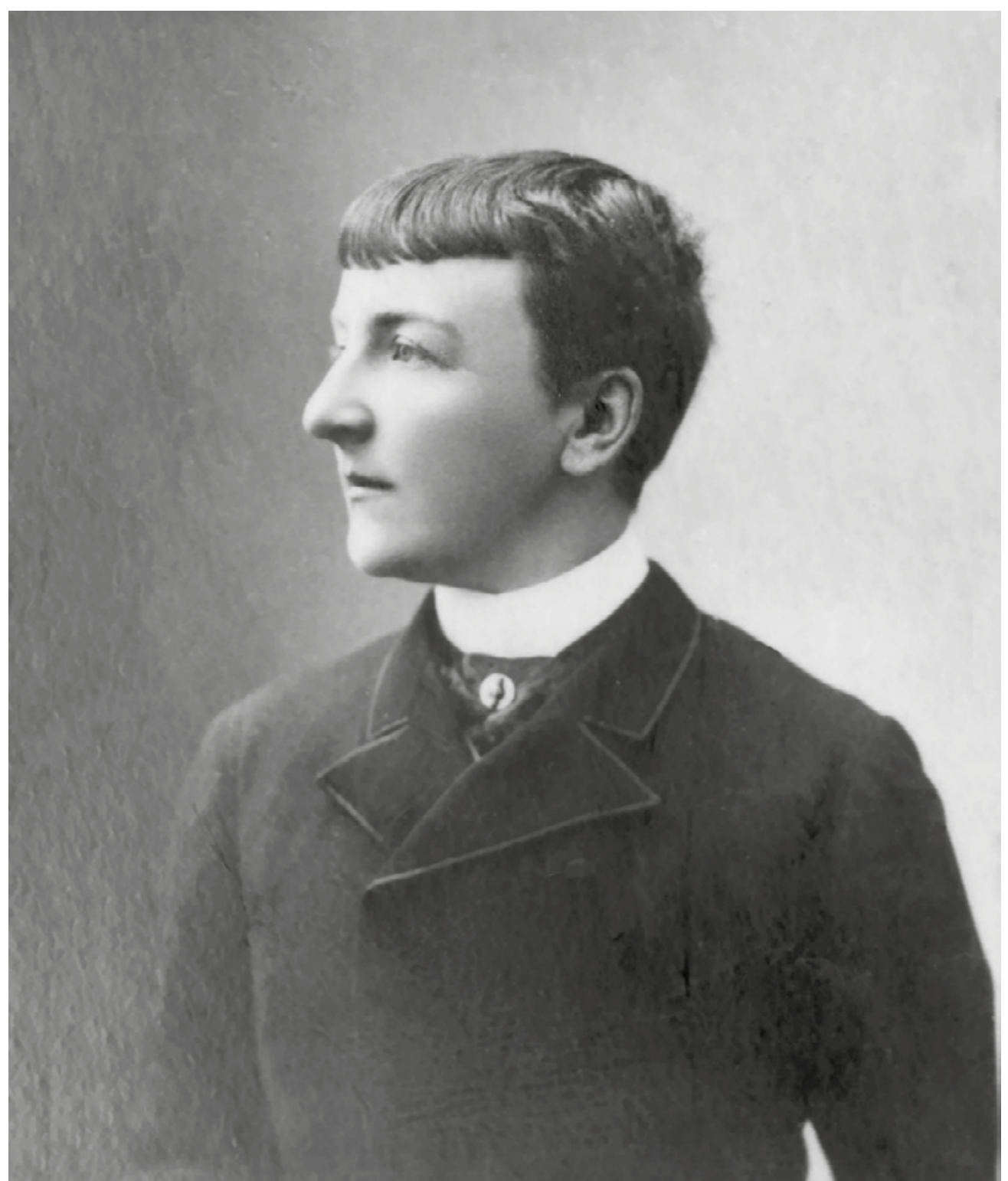

FUENTE: https://commons.wikimedia.org/wiki/Category:Jane_Dieulafoy\#/media/File:Jane_Dieulafoy_ photo.jpg. Acceso en: 4 abr. 2020.

Además, Dieulafoy combatió en la guerra franco-prusiana, en una compañía de francotiradores. Este tipo de alistamientos fueron promovidos en la época. Muestra de ello es el grabado publicado en 1872 titulado La voluntaria, oficial en el ejército regular. En él se representa la extravagante imagen de una combatiente con el pelo corto y una mirada que deja entrever un leve destello de locura. Sin embargo, lo que más llama la atención es que, el encontrarse rodeada de explosiones, no le impide lucir unos botines altos con tacones. A su lado, un soldado la contempla con cierta -y comprensible- estupefacción (BARD, 2012, p. 127-128). Imagen de guerrera con tacones que recuerda al look que lució Zendaya en la MET Gala de 2018. Su vestido, diseñado por Versace e inspirado, una vez más, en la Doncella de Orleans, logró atraer las miradas de todos los allí presentes (figura 19). 
FIGURA 19 - ZENDAJA VESTIDA POR VERSACE EN LA MET GALA DE 2018

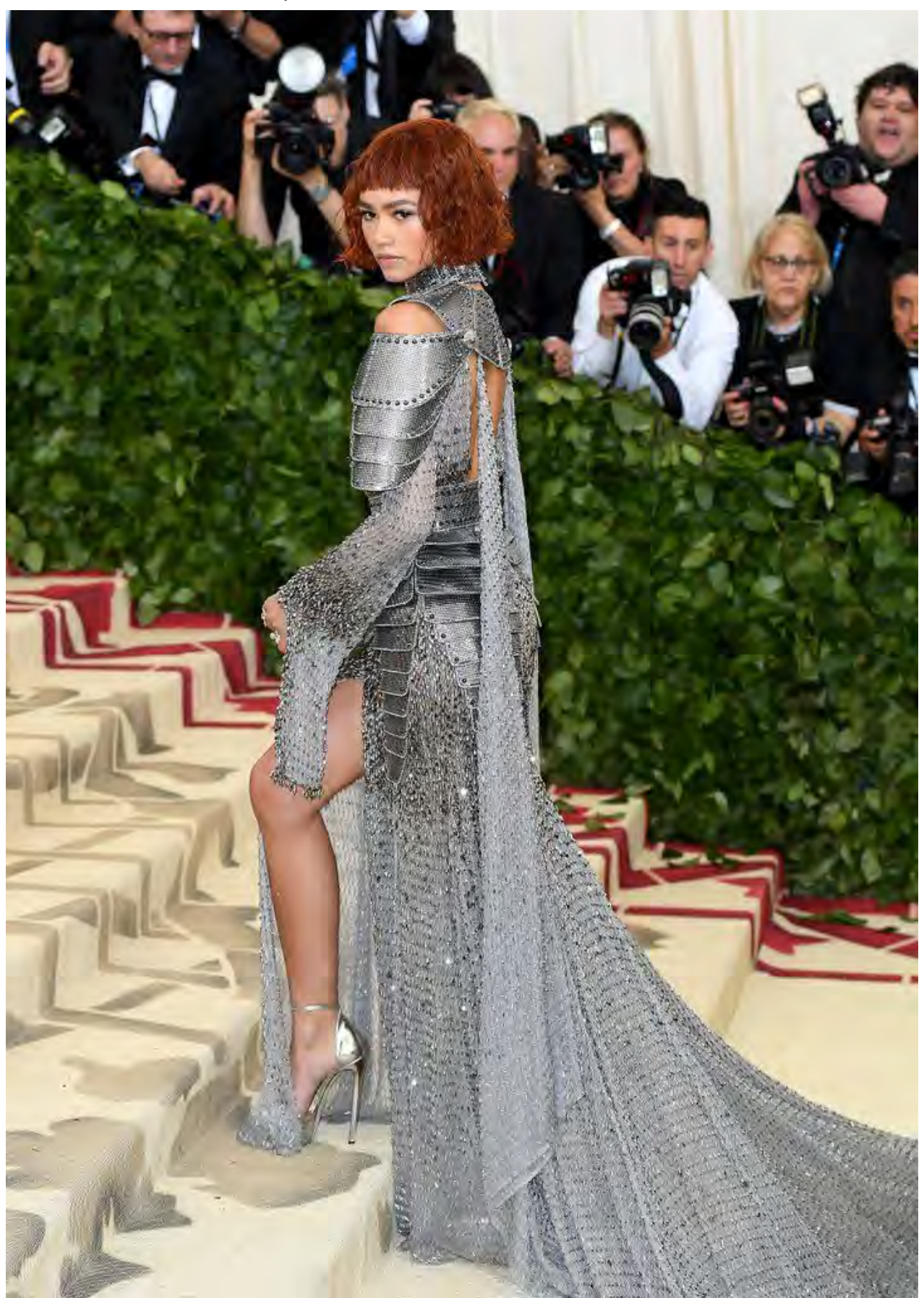

FUENTE: https://www.pinterest.es/pin/709457747524242580/. Acceso en: 4 abr. 2020.

En lo que respecta al cabello corto, cabe señalar que este, adoptado por las garçonnes y las flappers, será una constante en el proceso de virilización de la imagen de la mujer. Recordemos, por ejemplo, el Autorretrato con pelo corto (1940) de Frida Kahlo. Tras su separación de Diego Rivera, la artista se sentía querida tan solo por sus atributos femeninos, por lo que decidió sustituir su habitual ropa de Tehuana por un amplio traje de hombre, a la 
vez que se deshizo de su larga cabellera, como ya había hecho en 1934/1935, tras descubrir que su marido le era infiel con su hermana Cristina. Sin embargo, Frida le dio un cierto toque de humor a su obra, al incluir en la parte superior del lienzo un fragmento de un corrido de la época: "Mira que si te quise, fue por el pelo, ahora que estás pelona, ya no te quiero" (figura 20).

FIGURA 20 - FRIDA KAHLO, AUTORRETRATO CON PELO CORTO, 1940. MUSEO FRIDA KAHLO

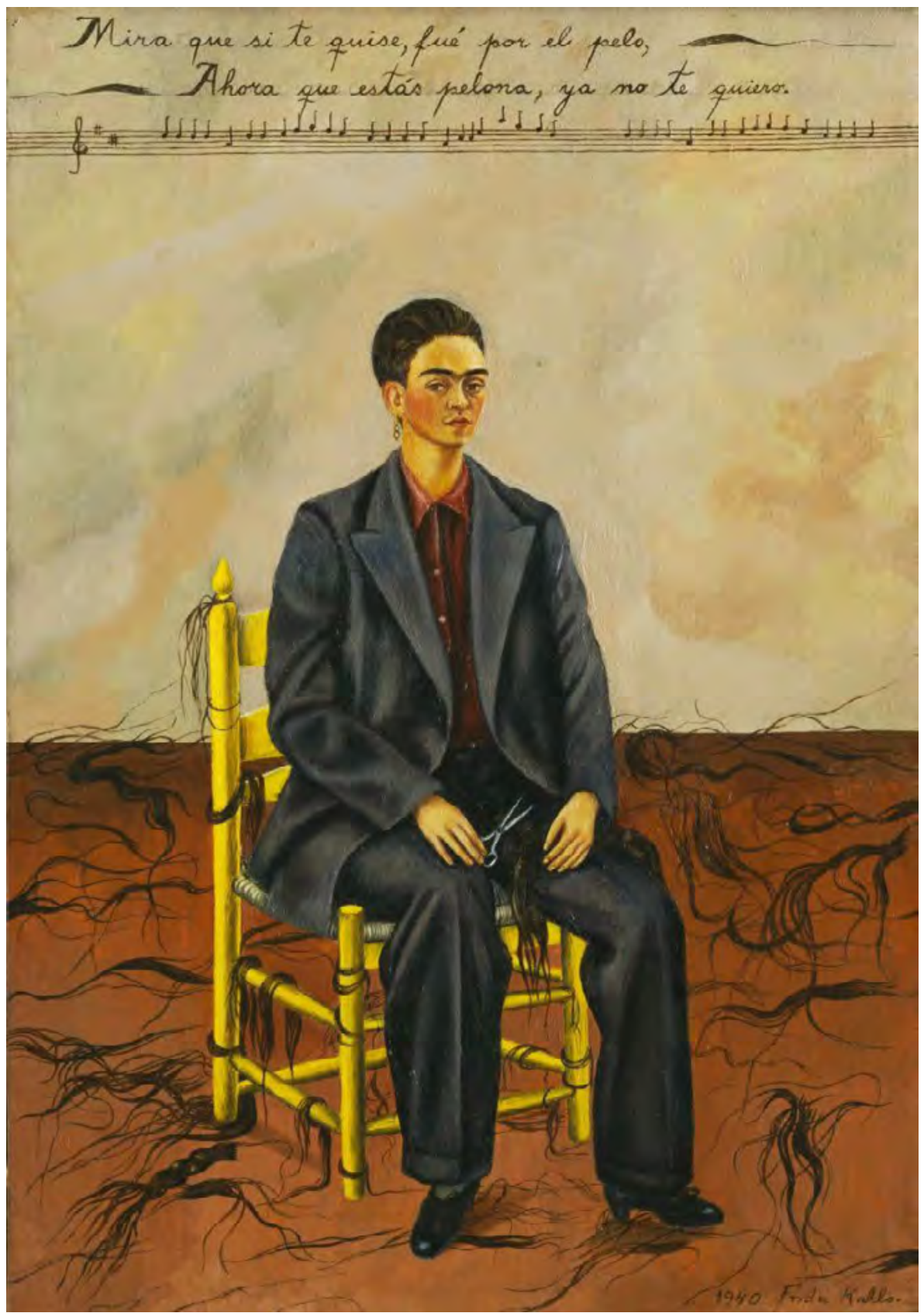

FUENTE: https://www.pinterest.com.mx/pin/557601997603395354/ Acceso en: 4 abr. 2020. 
No obstante, esta no era la primera vez que la artista adoptaba una estética marcadamente andrógina, como lo atestiguan algunas fotografías de la época, como, por ejemplo, la tomada por su padre, Guillermo Kahlo, el 7 de enero de 1926. En ella, Frida, vestida con un traje gris de hombre, aparece retratada junto a sus hermanas Adriana y Cristina, su prima Carmen Romero y Carlos Veraza (KETTENMANN, 1999, p. 11) (figura 21).

FIGURA 21 - FRIDA KAHLO CON SUS HERMANAS, SU PRIMA Y CARLOS

VERAZA, 1926. FOTOGRAFÍA DE GUILLERMO KAHLO

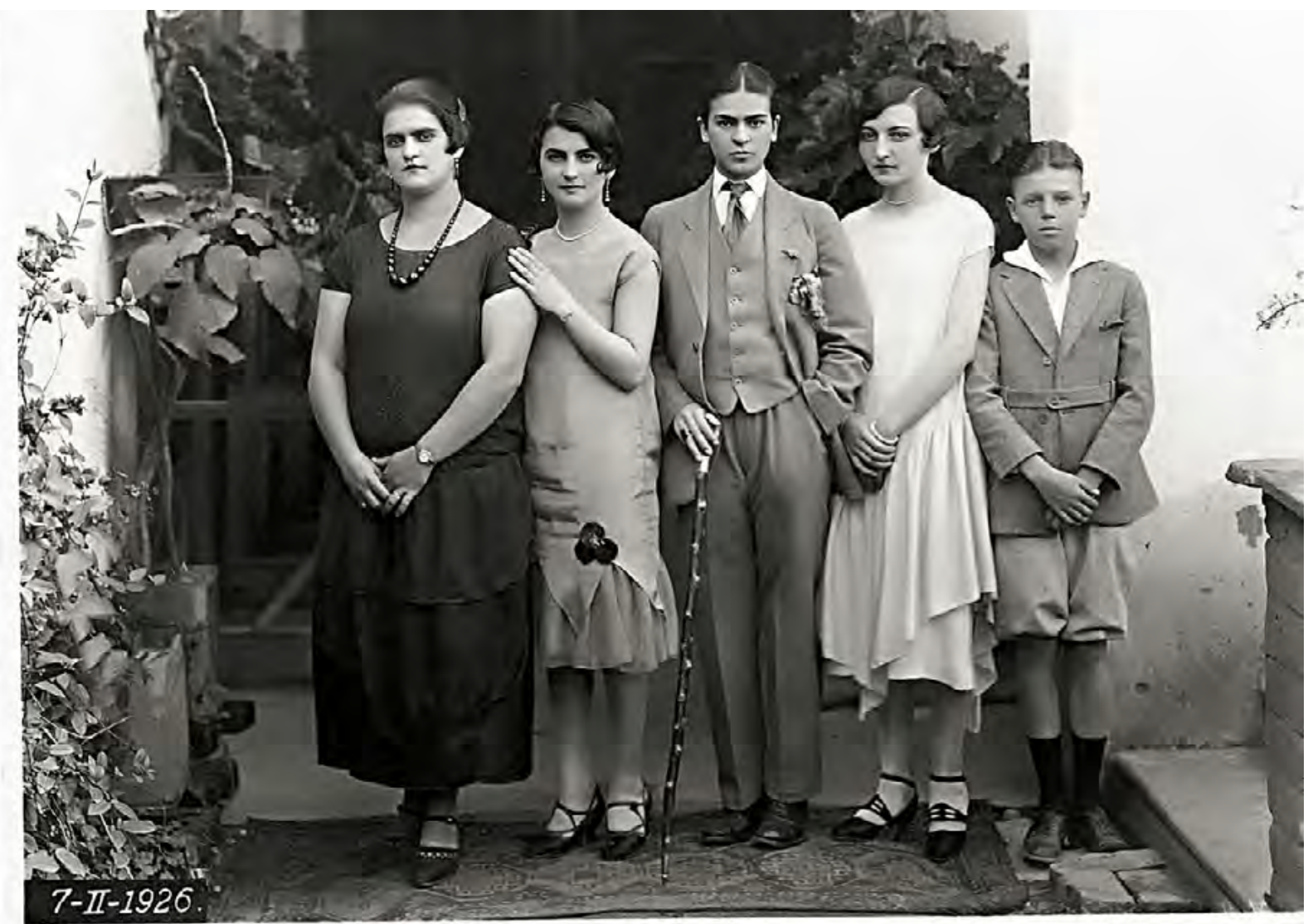

FUENTE: El País. Disponible en: https://smoda.elpais.com/wp-content/uploads/2016/05/2BernardSilberstein-courtesy-Throckmorton-Fine-Art-New-York.jpg. Acceso en: 4 abr. 2020.

Patti Smith, quien ha abogado siempre por un marcado aspecto andrógino, parece emular a su admirada Frida Kahlo en la fotografía tomada por Robert Mapplethorpe en la que la cantante, con gesto serio, mira fijamente a la cámara, mientras corta su cabello con las tijeras que sostiene en su mano izquierda. Smith narra en Just Kids como, al dar a luz, las enfermeras le amenazaron con cortar su larga melena morena, como castigo por su look beatnick y su comportamiento "inmoral". Tenía tan solo 19 años. Poco después, con motivo de la celebración del Memorial Day, fue a Philadelphia para visitar la estatua de Juana de Arco que hay junto al museo de arte. Fue en ese momento cuando Patti Smith prometió a su heroína, a la que había conocido a través de los libros de historia, y al bebé que acababa de dar en adopción, que haría algo con su vida (SMITH, 2010, p. 103). 
Una vez trasladada a Nueva York fue la propia artista quien decidió cortarse el pelo para mostrar públicamente que su aspecto físico y sexualidad tan solo le incumben a ella (figura 22). Encarnaba así a la "misplaced Joan of Arc" de su tema Kimberly:

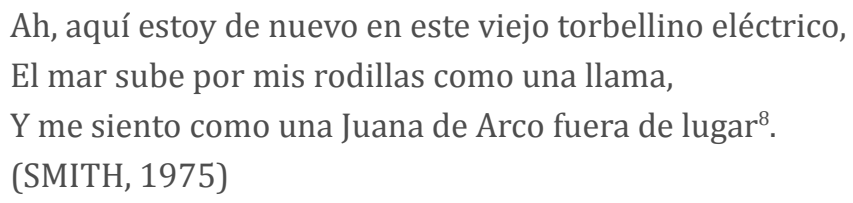

Esta canción se incluyó en su álbum debut Horses, publicado en 1975. El diseño de la cubierta corrió a cargo de Mapplethorpe, quien la fotografió luciendo un marcado aspecto masculino, con camisa, corbata, tirantes y una americana al hombro, al más propio estilo Frank Sinatra.

FIGURA 22 - PATTI SMITH FOTOGRAFIADA POR ROBERT MAPPLETHORPE (CA. 1970)

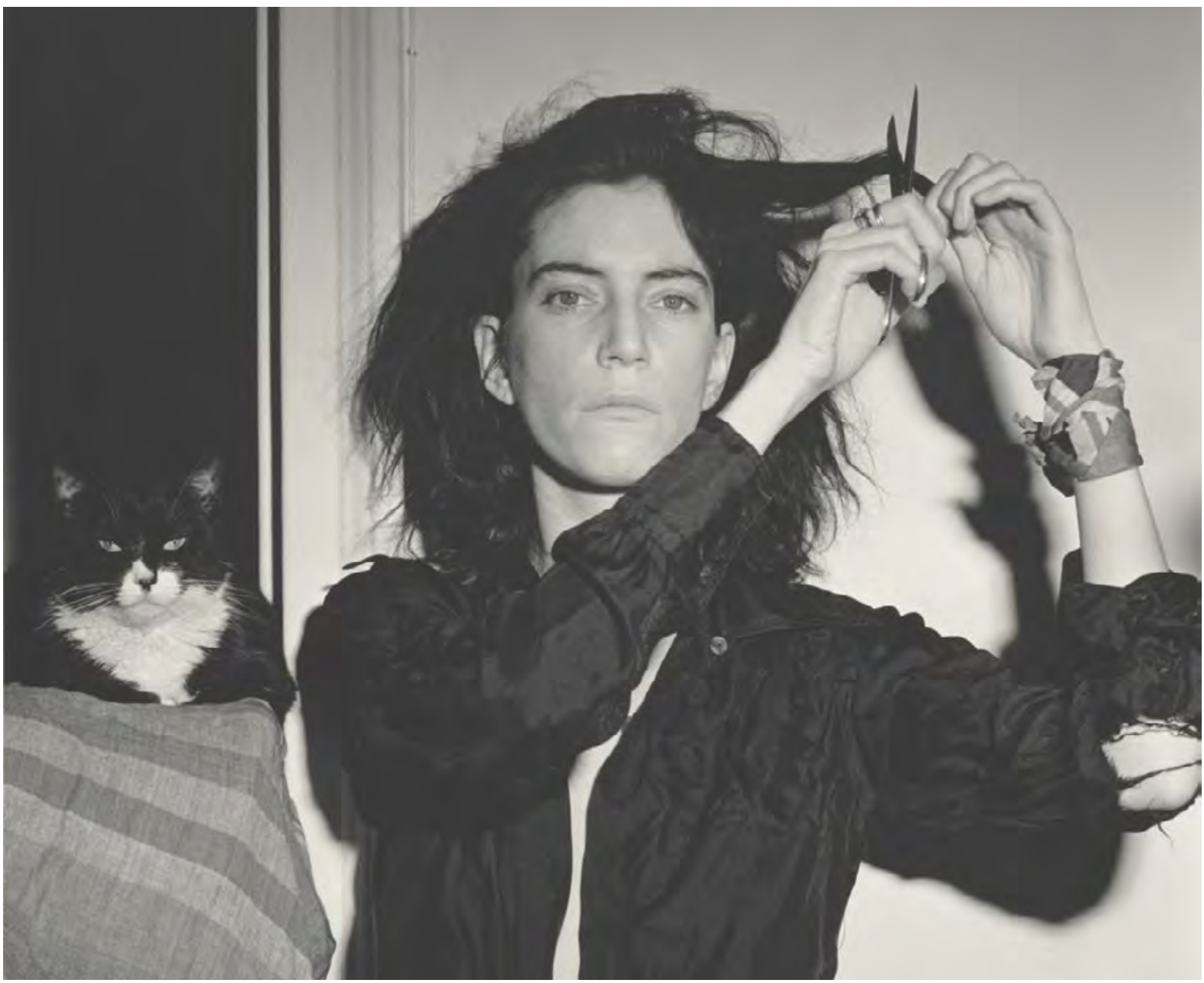

FUENTE: https://www.pinterest.es/pin/122089839871132040/. Acceso en: 4 abr. 2020.

${ }^{8}$ Tradução nossa para: "Ah, here I stand again in this old 'lectric whirlwind /The sea rushes up my knees like flame / And I feel like just some misplaced, Joan of Arc / And the cause is you lookin' up at me". 
El Power Dressing cobró especial relevancia a partir de la década de los 80 (HIBBERT, Clare y HIBBERT, Adam, 2005, p. 42; BARD, 2012, p. 300-305). Tan solo dos años antes, en 1978, John T. Molloy, “America's first wardrobe engineer", había publicado su exitosa obra The Woman's Dress for Success Book. Molloy tenía muy claro que una mujer jamás debe imitar a un hombre al vestir, puesto que, según él, un traje de tres piezas de raya diplomática no suma autoridad a las mujeres, sino todo lo contrario, la destruye. Afirmaciones cuyo autor asegura no estar basadas en el sexismo, sino en el realismo ("It is no sexism; it is realism"). De hecho, opina que la adopción, por parte de las mujeres, de un vestuario propiamente masculino era solo defendida por aquellas que trabajaban en la industria y por los diseñadores de moda meramente interesados en el éxito de sus carreras (MOLLOY, p. 28 y 32).

Uno de los diseñadores que apostó firmemente por la progresiva virilización del fondo de armario de la mujer fue Yves Saint Laurent quien, en 1966, y, por lo tanto, el mismo año que Rabanne lanzó su ya citada Colección Manifiesto, introdujo su mítico Le Smoking (otoño-invierno 1966-1967). Un juego de provocación y de trasgresión de los límites del género que, desde entonces, se convirtió en una de las principales señas de identidad de la firma (BREWARD, 2003, p. 90; BARD, 2012, p. 254, ENGLISH, 2013, p. 101-102) (figura 23).

\section{FIGURA 23 - LE SMOKING. COLECCIÓN OTOÑO/INVIERNO 1966-1967 DE YVES SAINT LAURENT}

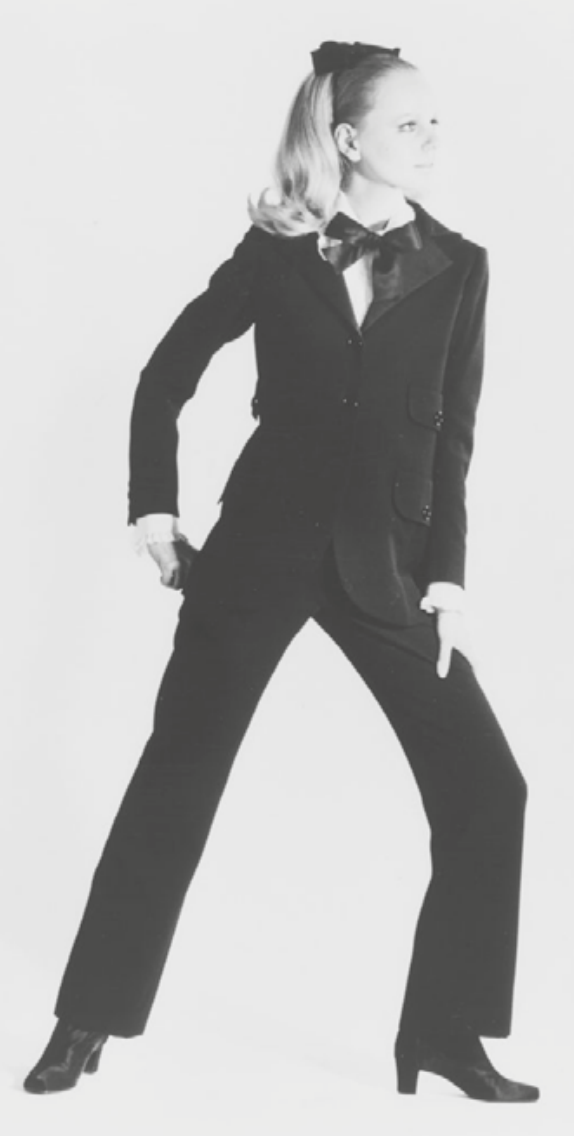

FUENTE: https://lustermagazine.com/aniversario-piezas-historicasyves-saint-laurent/. Acceso en: 4 abr. 2020. 
No obstante, el debate sobre si las mujeres podían o no vestir pantalones se remontaba a la década de los años 30. Concretamente, el número de mayo de 1933 de la revista Movie Classic incluía un artículo de Dorothy Calhoun con el siguiente titular: "Will It Be Trousers for Women?" (CALHOUN, 1933, p. 18-19, 62 y 64-65). Además de la mencionada actriz, figuras como Greta Garbo, Marlene Dietrich, Mozelle Britton o Fay Wray figuran en la lista de celebridades que se habían posicionado a favor de convertir el pantalón en una prenda indispensable en el armario de cualquier mujer. Al final del texto se incluyen declaraciones de uno de los miembros de Watson and Sons. Este asegura que, desde que se hizo público que eran los sastres de Marlene Dietrich, muchas mujeres se habían puesto en contacto con ellos para encargarles pantalones a medida. Asimismo, aseguraba que solían rechazar la mitad de estas peticiones puesto que tan solo estaban dispuestos a fabricar dicha prenda para las mujeres cuya silueta les permitiese lucirla correctamente:

\section{Nos negamos a confeccionar dichos trajes para casi la mitad de esas mujeres. Sal- vo que sepamos que la mujer tiene la silueta apropiada, y que le quedarán bien los pantalones, no aceptaremos los encargos ${ }^{9}$. \\ (CALHOUN, 1933, p. 65)}

Ese mismo año, el número de abril de la revista Modern Screen incluyó un artículo en el que Jean Cummings analizaba los motivos por los cuales Marlene Dietrich vestía pantalones (figura 24). La actriz aseguraba que prefería la ropa masculina ya que le resultaba mucho más cómoda. Además, afirmaba que estas prendas le daban un aspecto mucho más femenino que los vestidos y que para vestir elegantemente en Hollywood con prendas de mujer habría tenido que emplear mucho más tiempo y dinero (CUMMINGS, 1933, p. 38 y 113). Según Calhoun, la ya citada Amelia Earhart le había confesado a Marlene Dietrich que le gustaba el arriesgado estilo de la actriz puesto que consideraba que los pantalones eran una prenda práctica y cómoda para toda mujer moderna con una vida activa:

Los pantalones son una prenda práctica y cómoda para la mujer moderna que lleva una vida activa ${ }^{10}$.

(CALHOUN, 1933, p. 65)

\footnotetext{
9 Tradução nossa para: "We refuse to make such suits for about half of these women. Unless we know the woman has the proper figure, and will appear well in trousers, we will not make up the order".

10 Tradução nossa para: "Trousers are a practical and comfortable garment for the modern woman who leads an active life".
} 
FIGURA 24 - MARLENE DIETRICH PREPARÁNDOSE PARA UN SHOW DE LA USO (DICIEMBRE 1944)

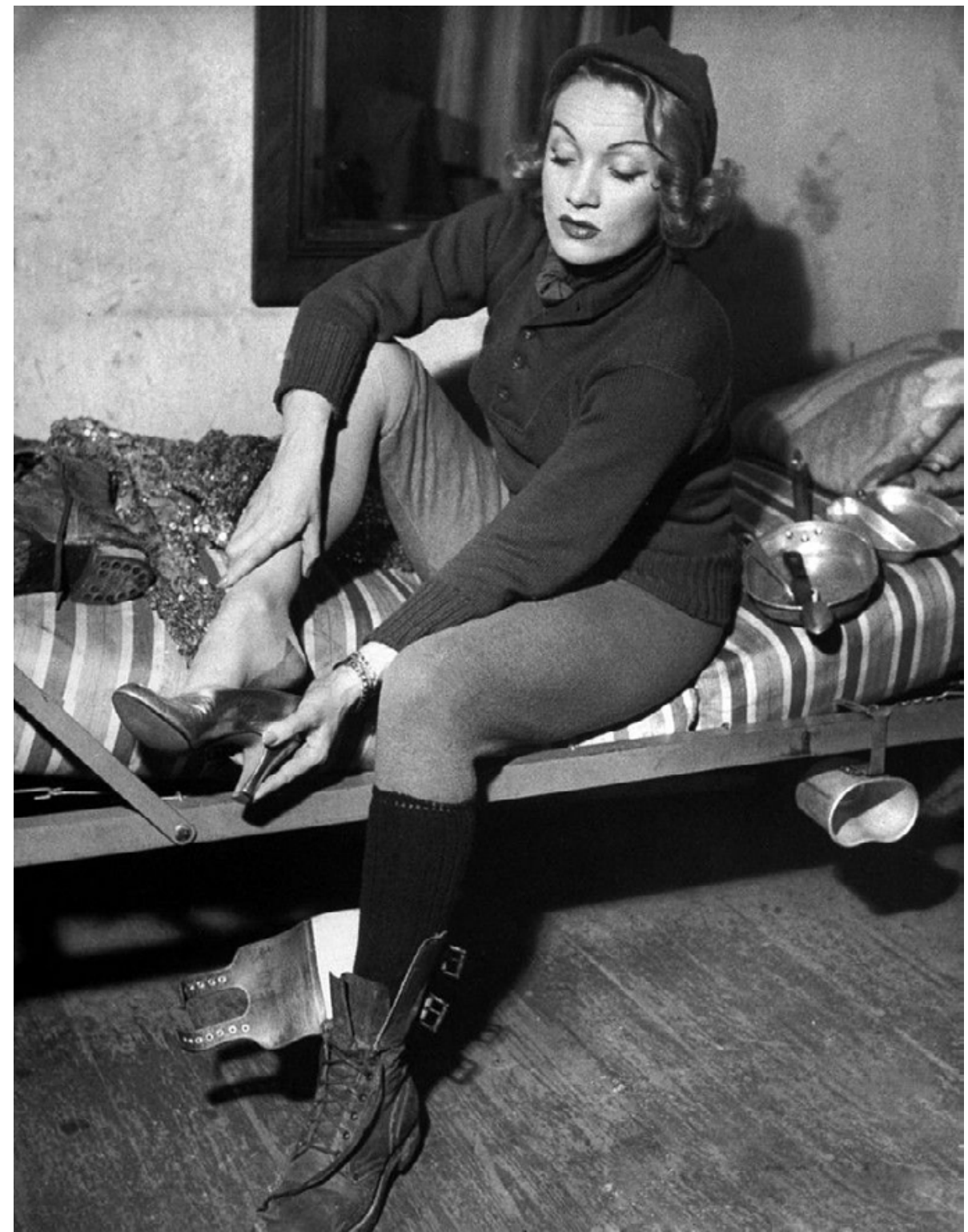

FUENTE: https://www.anothermag.com/fashion-beauty/10744/ten-things-you-might-not-know-aboutfemme-fatale-marlene-diet. Acceso en: 4 abr. 2020.

Una mujer moderna y activa cuya estética marcadamente masculina solía ir acompañada de unos zapatos bajos, tipo Oxford, con cordones, o bailarinas, y un cigarro encendido, presente en algunas de las fotografías más icónicas de Marlene Dietrich, Katharine Hepburn - quien se mantuvo fiel a dicha estética hasta el final de su vida (figura 25) -, o la propia Coco Chanel quien, a través de sus diseños, logró liberar el cuerpo de la mujer de la prisión de modas anteriores, invitando a sus clientas a imitarla, luciendo el cabello corto, los brazos bronceados y vistiendo prendas cómodas e informales, entre las que destacan los pantalones y las chaquetas de hombre (figura 26). Como declaró la propia diseñadora: 
En mi juventud, las mujeres no parecían humanas. Sus ropas eran contra natura. Yo les devolví su libertad. Les di brazos y piernas de verdad, movimientos que eran auténticos y la posibilidad de reír y comer sin tener necesariamente que desmayarse. (BARD, 2012, p. 234-235)

\section{FIGURA 25 - KATHARINE HEPBURN (1987)}

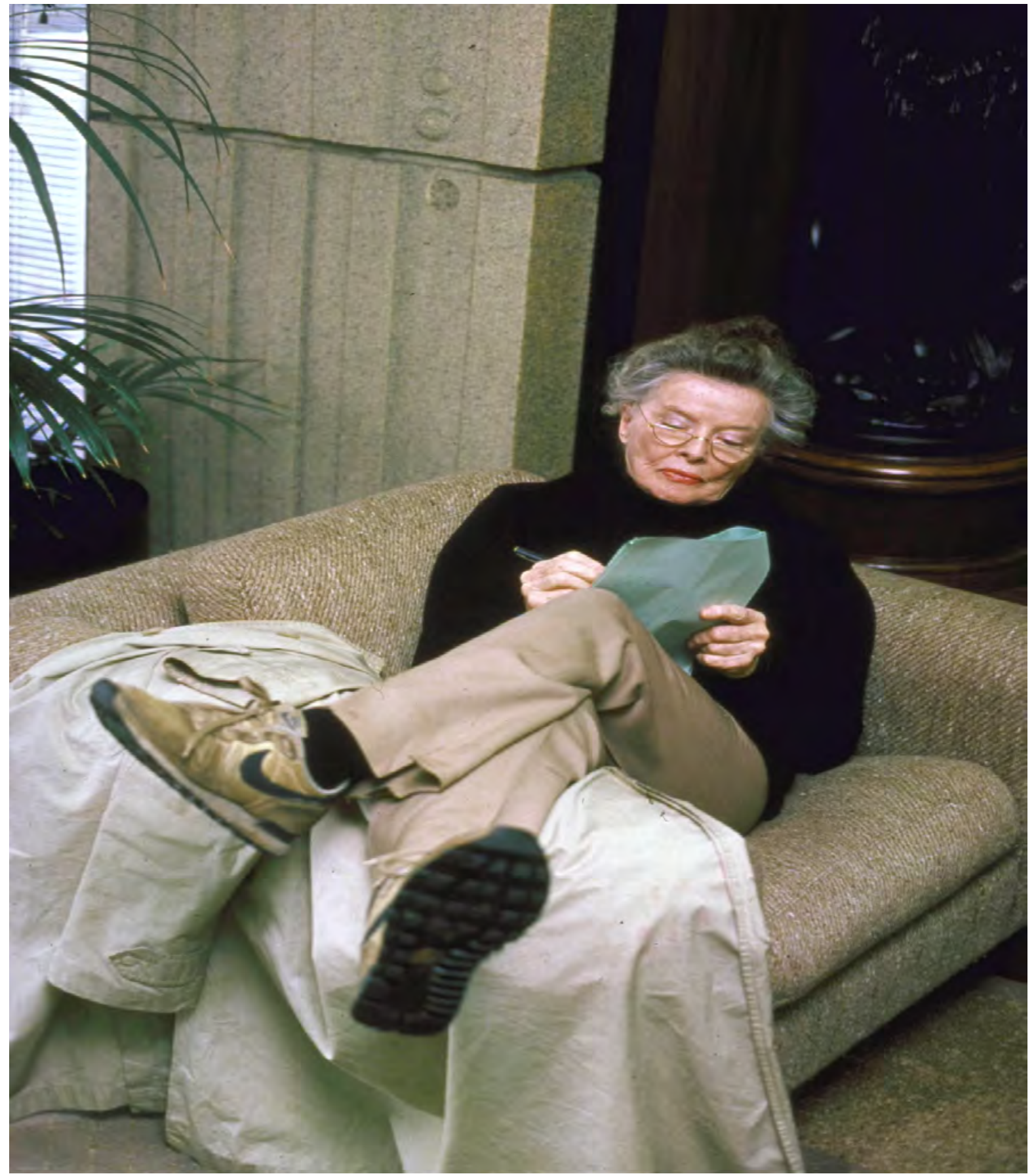

FUENTE: Revista Vogue. Disponible en: https://www.vogue.es/moda/articulos/ katharine-hepburn-zapatillas-nike. Acceso en: 4 abr. 2020. 


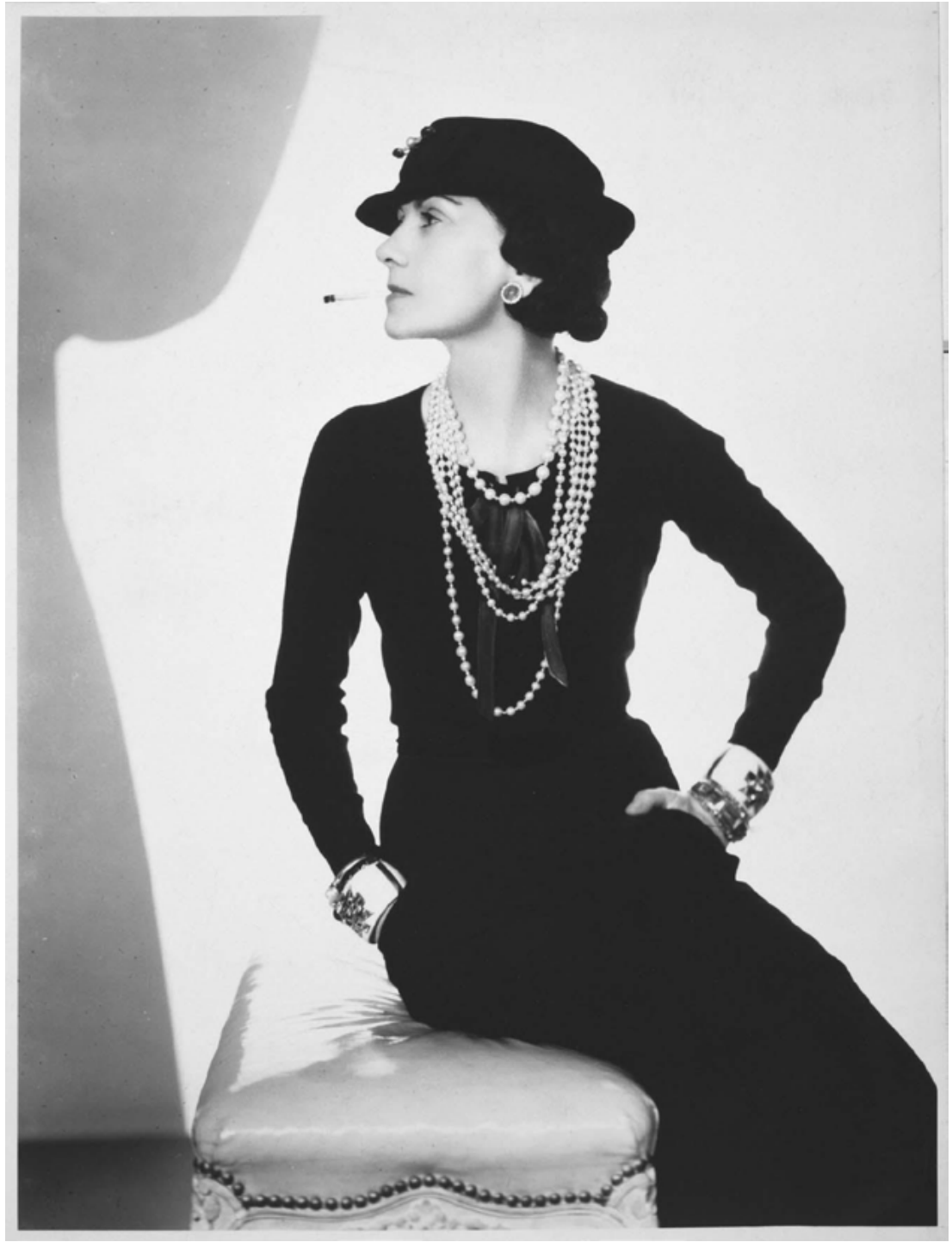

FUENTE: Museo Nacional Centro de Arte Reina Sofia. Disponible en: https://www.museoreinasofia.es/en/ collection/artwork/coco-chanel. Acceso en: 4 abr. 2020.

En 1934 Thalberg propuso a Greta Garbo interpretar a Juana de Arco, con un guión de Mercedes de Acosta. Sin embargo, la actriz renunció al papel, siendo 14 años más tarde, en 1948, Ingrid Bergman, la encargada de dar vida a la santa francesa, bajo la dirección de Victor Fleming (figura 27). El diseño del vestuario corrió a cargo de una mujer: Barbara Karinska, galardonada con el primer premio concedido en la historia de la Academia al Mejor Diseño de Vestuario (VICKERS, 1994, p. 330; BLATEZ, 2001, p. 125, 130-131, 135, 142 y 151-152; HUBABRD-BROWN, 2010, p. 100-101). Sin embargo, en esta ocasión, los diseños no aspiraban tanto a imitar la indumentaria medieval, como a acentuar la línea del muslo (BLAETZ, 2001, p. 131). De hecho, los distintos looks lucidos por Bergman influyeron profundamente en la moda de otoño de ese mismo año, como se puede apreciar en el artículo "Joan of Arc fashion", publicado el 20 de julio de 1948 en la revista Look: 
Las primeras acometidas en Juana de Arco, protagonizada por Ingrid Bergman, revelaron su importancia. Tan solo los colores son tan impresionantes que Burlington Mills destacará a Juana de Arco sombreada para otoño. Look eligió primeros planos con ideas de indumentaria que sin duda influirán en la ropa este otoño. Los bocetos de John Frederic muestran cómo ${ }^{11}$.

(BLAETZ, 2001, p. 132-134)

Como ha señalado Robin Blaetz, las prendas resultantes fueron meras "versiones domesticadas" de la mujer guerrera, cuya máxima aspiración en la vida se había visto, de nuevo, reducida, a mediados del siglo XX, a ser esposa y madre (BLAETZ, 2001, p. 132-134).

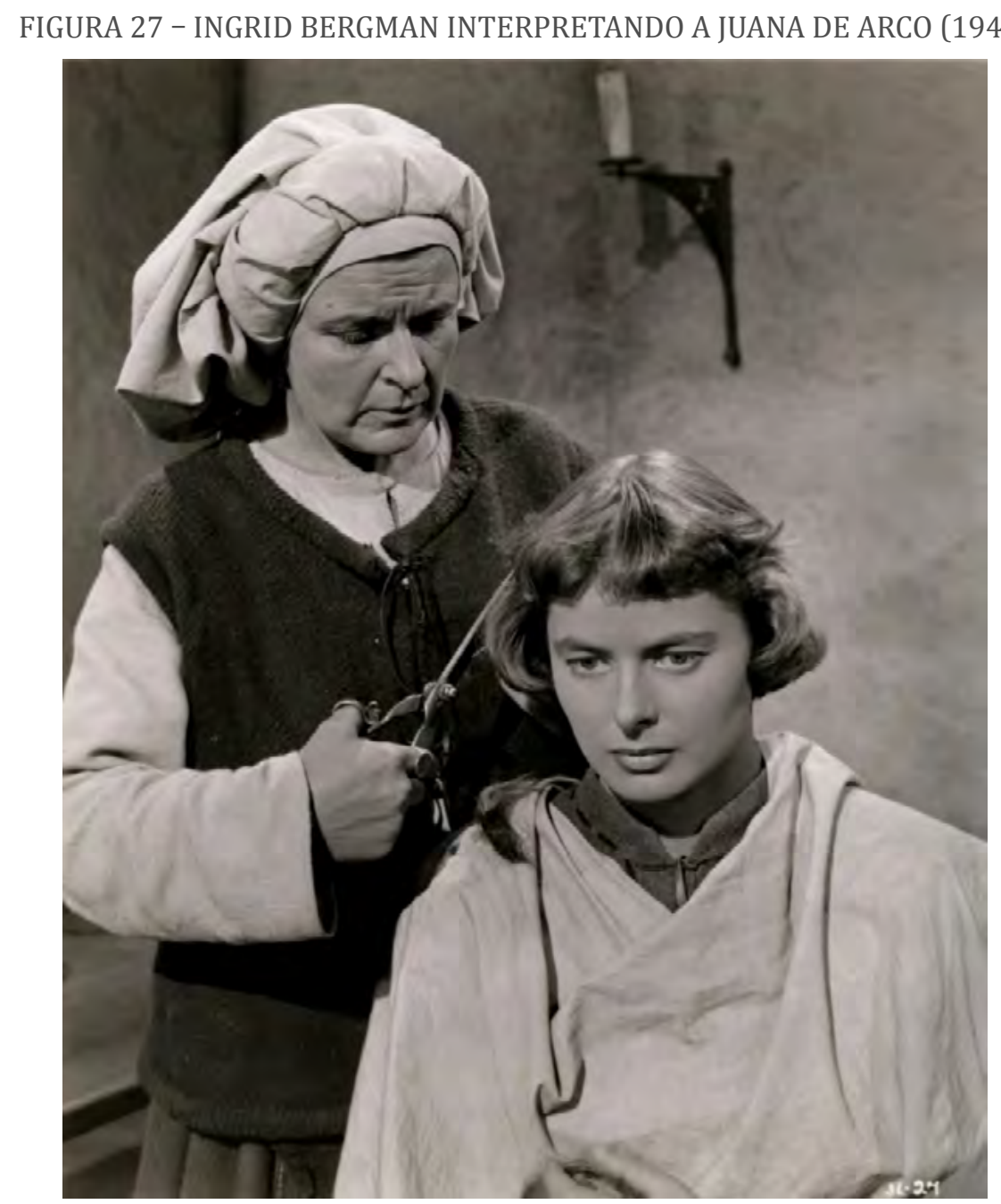

FUENTE: https://www.pinterest.ca/pin/452259987561938258/. Acceso en: 4 abr. 2020.

\footnotetext{
11 Tradução nossa para: First rushes on Joan of Arc, starring Ingrid Bergman, revealed its fashion importance. Colors alone are so impressive that Burlington Mills will high-light Joan of Arc shaded for fall. Look chose close-ups with costume ideas which will undoubtedly influence clothes this fall. John Frederic's sketches show how.
} 


\section{Consideraciones finales}

Como se ha podido comprobar, desde el siglo XV hasta la actualidad han sido innumerables las versiones creadas de Juana de Arco como referente estético, social y político. Su mito es una constante en la moda contemporánea y seguramente lo seguirá siendo en un futuro, en el que se continuarán explorando las distintas facetas de esta heroína medieval que representa a la perfección la fortaleza femenina y, ante todo, la multiplicidad de la mujer. Concepto este último defendido por figuras como la ya citada George Sand, quien afirmaba que "la mujer no existe. Solo hay mujeres cuyos tipos varían al infinito". Afirmación que queda puesta de manifiesto en el uso que las mujeres han hecho de la moda a lo largo de la historia, como un poderoso instrumento semántico de autodefinición y de construcción de su propia imagen, desprovisto de la aparente frivolidad de la que, en ocasiones, se le acusa. En definitiva, como defendía en El arte de ser mujer (1922) la escritora y activista en defensa de los derechos de la mujer, Carmen de Burgos, o Colombine, como firmó algunos de sus trabajos:

\footnotetext{
La moda, que los espíritus superficiales miran como cosa frívola, encierra un sentido profundo, que no han desdeñado tomar en cuenta sabios y psicólogos para completar los estudios sociológicos más serios, demostrando así que hasta en las cosas que parecen más triviales hay algo oculto, desconocido, que las agiganta y las ennoblece. Algo muy importante, muy recóndito, capaz de revelar por si solo toda el alma de una época, todas las costumbres y todo el espíritu de un pueblo. En este caso está el arte de la indumentaria: la moda. (BURGOS, 1920, p. 27)
}

En definitiva, como señaló Lidia Alejandra Vásques Velasco, en su trabajo sobre las ninfas, y el paganismo, en el imaginario de Lagerfeld, la investigación en el mundo de la moda, debe promover nuevas líneas de investigación que traten de combatir "el prejuicio de la banalidad" y que abran los estudios sobre esta al ámbito de la historia y de la historia del arte, pues, parece evidente que determinados conceptos "primitivos y ancestrales", o, como es el caso que nos ocupa, mitos y leyendas del pasado fueron, y siguen siendo, recuperados en las pasarelas, consolidándolos como parte de una "ideología actual y viva" (VÁSQUES, 2017, p. 95 y 106).

La complejidad de los estudios sobre indumentaria y moda fue ya puesta de manifiesto por Carmen Bernis, quien describió esta disciplina como "la aventura de buscar camino en una selva intrincada y oscura" y, sobre todo, destacó la necesidad de aproximarse siempre al ámbito de la moda con una rigurosidad y una metodología propiamente científicas, teniendo presente que "todas estas cosas no son tareas fáciles". Según Coco Chanel, "fashion is not something that exist in dresses only. Fashion is in the sky, in the street, fashion has to do with ideas, the way we live, what is happening". Por lo tanto, se podría concluir, como lo hizo Honoré Balzac en su Tratado de la vida elegante (1830), que "el hombre que en la moda solo ve moda, es un tonto" (BERNIS, 1979, p. 9; HAYE, 1994, p. 138; ALSTON y DIXON, 2014, p. 82). 


\section{Referencias}

ALSTON, Isabella y DIXON, Kathryn. Coco Chanel. North Carolina: TAJ Books International, 2014.

ANGULO ÍÑIGUEZ, Diego. Isabel la Católica. Sus retratos, sus vestidos y sus joyas. Discurso leído en el acto de apertura del curso académico de 1951. Santander: Universidad Internacional Menéndez Pelayo, 1951.

ANSON, John. The Female Transvestite in Early Monasticism: The Origin and Development of a Motif. Viator. Medieval and Renaissance Studies, v. 5, 1874, p. 1-32.

ARDEN, Heather M. Christine de Pizan's Ditié de Jehanne d'Arc. History, Feminism, and God's Grace. En Ann W. Astell y Bonnie Wheeler (eds.). Joan of Arc and Spirituality. Houndmills, Basingstoke, Hampshire y Nueva York: Palgrave Macmillan, 2003, p. 196-208.

ARENAL, Concepción. La mujer del porvenir. Madrid: Félix Perié, 1869.

BARD, Christine. Historia política del pantalón. Barcelona: Tusquets Editores, 2012.

BERNIS, Carmen. Trajes y modas en la España de los Reyes Católicos. II. Los hombres. Madrid: Instituto Diego Velázquez, CSIC, 1979.

BLAEKS, Robin. Visions of the Maid. Joan of Arc in American Film and Culture. Charlottesville y Londres: University Press of Virginia, 2001.

BOLTON, Andrew (con contribuciones de Tim Blanks y Susannah Frankel). Alexander McQueen. Savage Beauty. Nueva Yok: The Metropolitan Museum of Art, 2012.

BRASILLACH, Robert. Le procès de Jeanne d’Arc. París: Éditions de Paris, 1998.

BREWARD, Chris. Fashion. Oxford: Oxford University Press, 2003.

BURGOS, Carmen de. El arte de ser mujer. Belleza y perfección. Madrid: Sociedad Española de Librería, 1922.

CALHOUN, Dorothy. Will It Be Trousers for Women? Movie Classic, mayo 1933, p. 18-19, 62 y 64-65.

CHRISP, Peter. A History of Fashion and Costume. The Victorian Age. Londres: Bailey Publishing Associates, 2005.

COLE, Daniel James y DEIHL, Nancy. The History of Modern Fashion from 1850. Londres: Laurence King, 2015. 
CRANE, Susan. Clothing and Gender Definition: Joan of Arc. Journal of Medieval and Early Modern Studies, vol. 26, n. 2, 1996, p. 297-320.

CRANE, Susan. The Performance of Self. Ritual, Clothing, and Identity During the Hundred Years War. Philadelphia: University of Pennsylvania Press, 2002.

CUMMINGS, Jean. Why Dietrich Wears Trousers? Modern Screen, abril 1933, p. 38 y 113.

EDWARDS, Lydia. How to Read a Dress. A Guide to Changing Fashion from the 16 $^{\text {th }}$ to the $2^{\text {th }}$ Century. Londres y Nueva York: Bloomsbury, 2017.

ENGLISH, Bonnie. A Cultural History of Fashion in the $20^{\text {th }}$ and $21^{\text {st }}$ Centuries. Londres $y$ Nueva York: Bloomsbury, 2013.

FRAIOLI, Deborah. The Literary Image of Joan of Arc: Prior Influences. Speculum, v. 56, n. 4, 1981, p. 811-830.

GRIGAT, Daniel y CARRIER, Gregory. Gender Transgression as Heresy: The Trial of Joan of Arc. Past Imperfect, n. 13, 2007, p. 188-207.

HAYE, Amy de la. Chanel. The Couturiere at Work. Londres, V\&A Publications, 1994.

HOBBINS, Daniel. The Trial of Joan of Arc. Cambridge y Londres: Harvard University Press, 2005.

HORAK, Laura. Girls Will Be Boys. Cross-Dressed Women, Lesbians, and American Cinema, 1908-1934. New Brunswick, Nueva Jersey y Londres: Rutgers University Press, 2016.

HUBBARD-BROWN, Janet. Joan of Arc. Religious and Military Leader. Nueva York: Chelsea House Publishers, 2010.

JUNGNICKEL, Kat. Bikes and Bloomers. Victorian Women Inventors and Their Extraordinary Cycle Wear. Londres: Goldsmiths Press, 2018.

KETTENMANN, Andrea. Frida Kahlo, 1907-1954. Dolor y passion. Taschen: Colonia, 1999.

KING, Margaret L., y RABIL, Albert Jr. Her Immaculate Hand. Selected Works By and About The Women Humanists of Quattrocento Italy. Nueva York: Center for Medieval and Early Renaissance Studies - State University of New York at Binghamton, 1992.

KNOX, Kristin. Alexander McQueen. Genius of a generation. Londres: A\&C Black, 2010. 
MAYOR, Adrienne. Amazons. Lives \& Legends of Warrior Women Across the Ancient World. Princeton y Oxford: Princeton University Press, 2014.

MAYOR, Adrienne. Who Invented Trousers? Natural History, octubre 2014, p. 28-33..

MOLLOY, John T. The Woman's Dress for Success Book. Nueva York: Warner Books, 1978.

MORALES SEGURA, Cristina; SEGURA GRAIÑO, Cristina. La Querella de las Mujeres XIII. Christine de Pizan. Le Ditié de Juana de Arco. Madrid: Almudayna, 2014.

SEARS, Clare. Arresting Dress. Cross-Dressing, Law, and Fascination in NineteenthCentury San Francisco. Durham y Londres: Duke University Press, 2015.

VARGAS MARTÍNEZ, Ana. La Querella de las mujeres. Tratados hispánicos en defensa de las mujeres (siglo XV). Madrid: Fundamentos, 2016.

VÁSQUES VELASCO, Lidia Alejandra. Las ninfas de Lagerfeld: paganismo literario en Modern Mythology y The Little Black Jacket. Nierika. Revista de Estudios de Arte, n. 11, 2017, p. 94-107.

VICKERS, Hugo. Loving Garbo. The Story of Greta Garbo, Cecil Beaton y Mercedes de Acosta. Londres: Penguin Books, 1995.

WARNER, Marina. Joan of Arc. The Image of Female Heroism. Oxford: Oxford University Press, 2013. 